\title{
Gas chemical investigation of hafnium and zirconium complexes with hexafluoroacetylacetone using preseparated short-lived radioisotopes
}

\author{
By Ch. E. Düllmann ${ }^{1,2,3, *}$, K. E. Gregorich ${ }^{1}$, G. K. Pang ${ }^{1,2, \#}$, I. Dragojević ${ }^{1,2}$, R. Eichler ${ }^{4,5}$, C. M. Folden III ${ }^{2, \#,}$ \\ M. A. Garcia ${ }^{1,2}$, J. M. Gates ${ }^{1,2}$, D. C. Hoffman ${ }^{1,2}$, S. L. Nelson,\#\#, R. Sudowe ${ }^{1, \# \# \# ~ a n d ~ H . ~ N i t s c h e ~}{ }^{1,2}$ \\ ${ }^{1}$ Nuclear Science Division, Lawrence Berkeley National Laboratory, Berkeley, CA 94720, USA \\ 2 College of Chemistry, University of California, Berkeley, CA 94720-1460, USA \\ 3 Kernchemie, GSI Helmholtzzentrum für Schwerionenforschung GmbH, 64291 Darmstadt, Germany \\ ${ }^{4}$ Labor für Radio- und Umweltchemie, Paul Scherrer Institut, 5232 Villigen, Switzerland \\ 5 Departement für Chemie und Biochemie, Universität Bern, 3012 Bern, Switzerland
}

(Received December 2, 2008; accepted in revised form February 5, 2009)

\section{Zirconium / Hafnium / Hexafluoroacetylacetonates / Thermochromatography / Isothermal gas chromatogaphy / Physical preseparation}

Summary. Volatile metal complexes of the group 4 elements $\mathrm{Zr}$ and $\mathrm{Hf}$ with hexafluoroacetylacetonate (hfa) have been studied using short-lived radioisotopes of the metals. The new technique of physical preseparation has been employed where reaction products from heavy-ion induced fusion reactions are isolated in a physical recoil separator - the Berkeley Gas-filled Separator in our work - and made available for chemistry experiments. Formation and decomposition of $\mathrm{M}(\mathrm{hfa})_{4}(\mathrm{M}=\mathrm{Zr}$, Hf) has been observed and the interaction strength with a fluorinated ethylene propylene (FEP) Teflon surface has been studied. From the results of isothermal chromatography experiments, an adsorption enthalpy of $-\Delta H_{\mathrm{a}}=(57 \pm 3) \mathrm{kJ} / \mathrm{mol}$ was deduced. In optimization experiments, the time for formation of the complex and its transport to a counting setup installed outside of the irradiation cave was minimized and values of roughly one minute have been reached. The half-life of ${ }^{165} \mathrm{Hf}$, for which conflicting values appear in the literature, was measured to be $(73.9 \pm 0.8) \mathrm{s}$. Provided that samples suitable for $\alpha$-spectroscopy can be prepared, the investigation of rutherfordium (Rf), the transactinide member of group 4, appears possible. In the future, based on the studies presented here, it appears possible to investigate short-lived single atoms produced with low rates (e.g., transactinide isotopes) in completely new chemical systems, e.g., as metal complexes with organic ligands as used here or as organometallic compounds.

\footnotetext{
*Author for correspondence (E-mail: c.e.duellmann@gsi.de).

\# Present address: Department of Chemistry and National Superconducting Cyclotron Laboratory, Michigan State University, East Lansing, MI 48824, USA.

"\# Present address: Cyclotron Institute, Texas A\&M University, College Station, TX 77843, USA.

\#\#\# Present address: Chemical Sciences Division, Lawrence Livermore National Laboratory, Livermore, CA 94551, USA.

\#\#\# Present address: Department of Health Physics, University of Nevada Las Vegas, Las Vegas, NV 89154-3037, USA.
}

\section{Introduction}

\subsection{Gas phase chemistry with transactinides}

Gas phase chemical methods have proven powerful for the investigation of the heaviest elements, called the transactinides (TAN, $Z \geq 104$ ). For recent reviews, see $[1,2]$. These elements are produced as evaporation residues (EVRs) in heavy-ion induced nuclear fusion reactions. Simple inorganic species like (oxy)halides, hydroxides or oxides have been studied for elements up to hassium (Hs, element 108). Recently, element 112 was investigated in a gas phase chemistry experiment in its elemental state [3]. Single atoms of these elements were either transported to a chemistry setup with a gas-jet, i.e., attached to aerosol particles that are suspended in rapidly flowing carrier gas [4-8] or as volatile species after thermalization in a gas mixture containing the reactive component $[9,10]$. Element 112 was transported in its volatile elemental state [3]. Inherent to both of these approaches are harsh conditions as far as chemistry is concerned: either high temperatures are needed to release the species from the aerosol particles used in the gas-jet; or a plasma is present, which is formed by the intense heavyion beam that is passing through the gas volume where the EVRs are thermalized. These conditions prevented studies of more complex molecules like organometallic compounds or volatile metal complexes which are generally rather thermally unstable.

\subsection{Physical preseparation for chemistry experiments}

Recently, the method of physical preseparation [11-14] has been developed to overcome these technical limitations. In this technique, the EVRs are spatially separated in a physical recoil separator from unwanted nuclear reaction products as well as the intense heavy-ion beam. The EVRs are then guided to a so-called recoil transfer chamber (RTC) [12, 15], a gas-filled volume in which they are thermalized. The RTC is isolated from the vacuum or low pressure gas atmosphere of the separator through a thin foil referred to as the RTC 
window. The EVRs penetrate this window if their kinetic energy (from full momentum transfer of the beam) is sufficiently high. The pertinent advantages of the technique are i) the beam-free environment in the RTC, and ii) the strong reduction of unwanted nuclear reaction products. The beam-free environment promises to allow studying thermally unstable chemical species. The absence of most unwanted background species was already exploited in liquid phase studies of rutherfordium (Rf, element 104) [11, 16, 17] where physical preseparation from isotopes that interfere with the unambiguous identification of single atoms of the heaviest elements through detection of their characteristic radioactive decay was essential, and in extraction studies of group 4 elements with crown ethers [18]. The potential that physical preseparation offers in the field of TAN chemistry has been recognized and has led to the upgrade of existing recoil separators such as i) the Berkeley Gas-filled Separator (BGS) [19] installed at the Lawrence Berkeley National Laboratory, Berkeley, CA, US $[12,15]$, ii) the GAs-filled Recoil Ion Separator (GARIS) [20,21] at the RIKEN laboratory, Wako, Saitama, Japan, and iii) the Dubna Gas-Filled Recoil Separator (DGFRS) [22] at the Flerov Laboratory of Nuclear Reactions, Dubna, Russia, so that they can now be used as preseparators. For a recent overview of physical separators used for studies of the heaviest elements, see [23].

\subsection{Choice of the chemical system}

\subsubsection{The group 4 elements}

In this work, conducted at the Lawrence Berkeley National Laboratory, the possibility of investigating new compound classes of the heaviest elements in the gas phase was studied. We used the BGS as a physical preseparator [12]. The group 4 elements, of which $\mathrm{Rf}$ is the heaviest member [1,2] were chosen for initial experiments. Rf has two advantages over other TAN elements. First, because the cross sections for producing TAN are decreasing with increasing $Z, \mathrm{Rf}$ as the lightest TAN is the one that can be produced with highest rates. Second, two $\mathrm{Rf}$ isotopes can be produced that appear suitable for chemical investigations. One is ${ }^{257} \mathrm{Rf}$, which is best produced in the cold fusion reaction ${ }^{208} \mathrm{~Pb}\left({ }^{50} \mathrm{Ti}, n\right)$ with a cross section of a few tens of nb [24, 25]. Known states in ${ }^{257} \mathrm{Rf}$ with half-lives of about $4 \mathrm{~s}$ and about $7 \mathrm{~s}$ [25] are both populated when this nuclide is produced as an EVR. The ${ }^{257} \mathrm{Rf}$ EVRs are rather fast due to the use of a heavy beam particle, which is advantageous because it allows for the use of a relatively thick RTC window. The other isotope is 68-s ${ }^{261 a} \mathrm{Rf}$ [26-28]. (Note that recently another, shorter-lived nuclear state has been observed in ${ }^{261} \mathrm{Rf}[29,30]$.) ${ }^{261 a} \mathrm{Rf}$ can only be produced in asymmetric reactions with light beams and actinide targets, e.g., in the reactions ${ }^{244} \mathrm{Pu}\left({ }^{22} \mathrm{Ne}, 5 n\right)$ with a cross section of about $4 \mathrm{nb}[31]$ or ${ }^{248} \mathrm{Cm}\left({ }^{18} \mathrm{O}, 5 n\right)$ with a cross section of about $13 \mathrm{nb}$ [32]. EVRs from such reactions are generally very slow and thus, more sophisticated RTC windows that i) are thin enough that these EVRs can penetrate them with $100 \%$ efficiency, ii) can withstand a substantial pressure difference, and iii) have a very small leak rate for He, which is typically used in the RTC, are needed. Also the targets are highly radioactive and require special

precautions for their safe irradiation. Note that the production of ${ }^{261} \mathrm{Rf}$ with ${ }^{238} \mathrm{U}$ targets in the reaction ${ }^{238} \mathrm{U}\left({ }^{26} \mathrm{Mg}, 3 n\right)$ was recently reported [33], but with a very small cross section of only $\sim 30 \mathrm{pb}$. This is almost three orders of magnitude smaller than the cross section obtained in, e.g., the reaction ${ }^{248} \mathrm{Cm}\left({ }^{18} \mathrm{O}, 5 n\right)$ [32] and thus, the ${ }^{238} \mathrm{U}$-based reaction is not a viable option for chemical studies of $\mathrm{Rf}$ using ${ }^{261} \mathrm{Rf}$. The choice of which isotope should be utilized is thus between a fast short-lived isotope and a slow long-lived one.

As a member of group 4, Rf is a homolog of zirconium $(\mathrm{Zr})$ and hafnium (Hf). So far, gas chemical investigations have been conducted with the tetrachloride [26,34-36] and the tetrabromide $[36,37]$ of Rf. The use of preseparated isotopes of the group 4 elements should permit use of organic ligands, which has not been an option so far. ${ }^{257} \mathrm{Rf}$, which was physically preseparated in the BGS, has already been successfully used in liquid phase chemistry experiments $[11,16]$. Unlike in those experiments, which used preseparated isotopes to take advantage of the reduced background, we are aiming at investigating new, thermally unstable compounds in the gas phase and use preseparation because it provides a beam free environment in the RTC.

\subsection{2 $\beta$-diketonates of $\mathrm{Zr}$ and $\mathrm{Hf}$}

A compound class that appears suitable for such studies is the $\beta$-diketonate metal complexes, i.e., coordination compounds of a metal with ligands of the structural type shown in Fig. 1b.

The presence of $\beta$-carbonyl groups with at least one proton on the intermediate carbon atom allows a tautomeric equilibrium of keto- and enol-forms (see Fig. 1a), which is the most important feature of $\beta$-diketones as it is the enolate anion which forms complexes with metals. The $\beta$-diketone enolate anions are well known to act as bidentate ligands forming neutral complexes with many elements. Some of these complexes can be transferred to the gas phase without decomposition [38]. Depending on the nature of $R_{1}$ and $R_{2}$, ligands with vastly different properties are known. A large variety of ligands has been synthesized and assessed with respect to their usefulness in gas chromatography of metal complexes [39]. Nowadays, many different ligands are commercially available. Systematic investigations of complexes of many elements using a variety of ligands have led to the observation that the introduction of fluorinated groups leads to enhanced volatility of the respective complexes $[38,40,41]$. Volatile $\beta$-diketonate complexes of many metals are widely used, e.g., as precursors for thin film production by the metal-organic chemical vapor deposition (MOCVD) method $[42,43]$. Among the best studied complexes are those using anions of 2,4-pentanedione (acetyl-

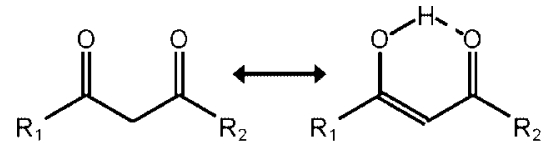

(a)

Fig. 1. (a) The $\beta$-diketones in their keto- (left) and enol- (right) form, and (b) the structure of their anions. 
acetone; acac; $\mathrm{R}_{1}=\mathrm{R}_{2}=\mathrm{CH}_{3}$ ) and its partially or fully fluorinated analogs, 1,1,1-trifluoro-2,4-pentanedione (trifluoroacetylacetone; tfa; $\mathrm{R}_{1}=\mathrm{CH}_{3}, \mathrm{R}_{2}=\mathrm{CF}_{3}$ ) and $1,1,1,5,5,5$ hexafluoro-2,4-pentanedione (hexafluoroacetylacetone; hfa; $\mathrm{R}_{1}=\mathrm{R}_{2}=\mathrm{CF}_{3}$ ) as ligands. The chemistry of fluorinated ligands has been reviewed [44]. The introduction of electronaccepting fluorine-containing groups greatly alters the distribution of electron density in the molecule, which shifts the keto-enol equilibrium towards the enol. In the case of hfa, this shift is complete and, in the neat liquid at $33^{\circ} \mathrm{C}, 100 \%$ of hfa is present in the enol-form [45]. Hfa is moisture sensitive; hydrolysis yields a stable tetrol $[46,47]$.

Due to their high volatility and stability, the hfa-complexes of $\mathrm{Zr}$ and $\mathrm{Hf}$ were chosen for first investigations with preseparated isotopes, keeping in mind that the system should be suitable for later experiments with Rf. $\mathrm{M}(\mathrm{hfa})_{4}(\mathrm{M}=\mathrm{Zr}$, Hf) are well known complexes [48] and have been investigated with respect to their usefulness as precursors for thin oxide film production of these metals [48]. $\mathrm{Zr}(\mathrm{hfa})_{4}$ is thermally stable (unlike $\mathrm{Zr}(\mathrm{tfa})_{4}$ and $\mathrm{Zr}(\mathrm{acac})_{4}$ [49]) and often employed in gas chromatography studies [50]. The $\mathrm{M}(\mathrm{hfa})_{4}$ complexes of $\mathrm{Zr}$ and $\mathrm{Hf}$ are also very similar in other chemical properties [48]: i) both are moisture sensitive, ii) they cannot be separated by gas chromatography owing to their very similar volatility, iii) thermogravimetric analysis (TGA) experiments gave indications for partial decomposition at $146-147^{\circ} \mathrm{C}$, iv) their boiling points were determined to be about $230^{\circ} \mathrm{C}$, and v) the complexes of both metals decompose at $500-600^{\circ} \mathrm{C}$ to form monoclinic dioxides.

\subsection{Aspects of atom-at-a-time studies}

In our work, we are solely concerned with the investigation of microamounts of metals as there is currently no method available that allows the production of macroamounts of Rf. We therefore studied $\mathrm{Hf}$ and $\mathrm{Zr}$ under the conditions of a potential future $\mathrm{Rf}$ experiment, i.e., using short-lived radioisotopes that were produced in heavy-ion induced fusion reactions. Earlier studies that used single shortlived atoms for studying $\beta$-diketonates in the gas-phase have been reported. Travnikov et al. separated ${ }^{95} \mathrm{Zr}$ from ${ }^{95} \mathrm{Nb}$ in the form of hfa complexes and achieved separation factors $>2 \times 10^{3}$ [51]. Ono et al. investigated complexes of 2,2,6,6-tetramethyl-3,5-heptanedione (thd, also referred to as dipivaloylmethane, dpm, $\left.\mathrm{R} 1=\mathrm{R} 2=\mathrm{C}\left(\mathrm{CH}_{3}\right)_{3}\right)$ with ruthenium $(\mathrm{Ru})$ and rhodium $(\mathrm{Rh})$ [52], the lighter homologs of hassium (Hs, element 108) and meitnerium (Mt, element 109) using short-lived $\mathrm{Ru}$ and $\mathrm{Rh}$ isotopes produced in a ${ }^{252} \mathrm{Cf}$ fission fragment source. Fedoseev et al. reported the preparation of volatile hfa-complexes of mendelevium ( $\mathrm{Md}$ ) and fermium (Fm) using 1.3-h ${ }^{256} \mathrm{Md}$ and its electron capture decay daughter $2.6-\mathrm{h}{ }^{256} \mathrm{Fm}$ where heterophase ligand exchange in ligand vapor containing carrier gas was employed [53]. Greulich et al. used a non-carrier-added mixture of several lanthanides obtained from thermal-neutron-induced fission of ${ }^{235} \mathrm{U}$ to investigate the fast separation of the lanthanides from each other with a combination of solvent extraction and gas chromatography of these elements, e.g., in the form of hfa-complexes [54]. Their technique is applicable to the separation of actinides (including preparation of thin samples suitable for $\alpha$-spectroscopy) on a time-scale of a few minutes.

Fedoseev et al. investigated the interaction of scandium $(\mathrm{Sc})$, ytterbium $(\mathrm{Yb})$, and $\mathrm{Hf}$ produced in heavy-ion induced nuclear fusion reactions with acac, tfa, and hfa [55]. These elements served as models for heavy actinides and Rf. Using relatively long-lived isotopes, it was demonstrated that these elements formed highly volatile complexes with hfa. In a temperature gradient tube, these were found to deposit at temperatures below $100^{\circ} \mathrm{C}$. However, two major problems were encountered in these experiments: first, passing the hfa enriched carrier gas through the recoil chamber (where the heavy-ion beam passed through) led to the radiolytical decomposition of the organic ligand. The decomposition products formed aerosol particles that led to nonchemically-selective transport of all products of the nuclear reaction to the detection system. The authors of [55] therefore split the gas stream into two fractions. The ligandfree fraction passed through the recoil chamber and served to transport the recoiling nuclear reaction products to the exit of the chamber. The other fraction, which was enriched in ligand vapor, bypassed the chamber. The two gas streams were merged at the exit of the recoil chamber. This procedure can be expected to result in reduced yields, especially when short-lived isotopes are used, which is not acceptable in a TAN experiment where the element under study is available in quantities of single atoms only. Secondly, their experiments did not achieve separation of the three studied elements since all of them form highly volatile complexes with hfa. This is a severe problem since the production of transactinides is always accompanied by the production of orders of magnitude more unwanted nuclides in, e.g., nuclear transfer reactions or reactions of the beam with the target assembly or impurities in the target material. Some of these unwanted products, especially $\alpha$-decaying Po isotopes and heavy actinides with a substantial spontaneous-fission branch, interfere with the unambiguous identification of the TAN element under study. Separation of Po and actinides is crucial in the chemical study of Rf.

The method of preseparation represents a significant step forward as it eliminates both these problems: the EVRs are separated from the beam in the physical preseparator and the conditions in the RTC are mild. At the same time, most of the transfer products are also removed in the separator and thus relatively clean beams of the desired EVRs enter the RTC.

With respect to the investigation of Rf, the kinetics of the chemical reaction leading to the volatile species is a crucial factor. The half-life of the longest-lived known Rf isotope that can be produced and preseparated, ${ }^{261 a} \mathrm{Rf}$, is $68 \mathrm{~s}$. Assuming typical values for target thickness, average beam intensity, and efficiency of the preseparator to guide formed EVRs to the RTC, the rates of ${ }^{257} \mathrm{Rf}$ and ${ }^{261 a} \mathrm{Rf}$ entering the RTC are of the order of $0.1-1 \mathrm{~min}^{-1}$. These minute rates, together with partial yields of each step involved in the chemical reaction and the detection of the nuclear decay of ${ }^{257} \mathrm{Rf}$ or ${ }^{261 a} \mathrm{Rf}$ of (for some steps significantly) less than $100 \%$ make it clear that only reactions that proceed on timescales of a few tens of seconds at most are acceptable. 
We therefore investigated the gas-phase formation of $\mathrm{M}(\mathrm{hfa})_{4}(\mathrm{M}=\mathrm{Zr}$, Hf) with respect to their potential for investigating $\mathrm{Rf}$ in the same chemical system. Using Hf radioisotopes with half-lives between some tens of seconds and several minutes allowed for the determination of the reaction time as a function of the reaction temperature, which was done over a large temperature range. Chemical speciation is difficult to achieve under the conditions of our experiments, and we therefore investigated the volatility of the involved chemical species using the well-known methods of isothermal gas chromatography [7] and thermochromatography (TC) [56], hoping that these results would give us information about the formed compound(s) by comparing its (or their) behavior to literature data.

\section{Experimental}

Over the course of about two years, relatively shortlived isotopes of $\mathrm{Zr}$ and $\mathrm{Hf}$ were studied in eighteen short blocks (16-32 h) of beamtime. The isotopes [57] ${ }^{85} \mathrm{Zr}\left(T_{1 / 2}=7.86 \mathrm{~min}\right),{ }^{162} \mathrm{Hf}\left(T_{1 / 2}=37.6 \mathrm{~s}\right),{ }^{165} \mathrm{Hf}\left(T_{1 / 2}=\right.$ $76 \mathrm{~s})$, and ${ }^{169} \mathrm{Hf}\left(T_{1 / 2}=3.24 \mathrm{~min}\right)$ were produced in the nuclear reactions ${ }^{\text {nat }} \mathrm{Ge}\left({ }^{18} \mathrm{O}, x n\right){ }^{85} \mathrm{Zr},{ }^{74} \mathrm{Se}\left({ }^{18} \mathrm{O}, \alpha 3 n\right){ }^{85} \mathrm{Zr}$, ${ }^{116} \mathrm{Sn}\left({ }^{50} \mathrm{Ti}, 4 n\right){ }^{162} \mathrm{Hf},{ }^{120} \mathrm{Sn}\left({ }^{50} \mathrm{Ti}, 5 n\right){ }^{165} \mathrm{Hf}, \quad{ }^{124} \mathrm{Sn}\left({ }^{50} \mathrm{Ti}, 5 n\right)$ ${ }^{169} \mathrm{Hf}$ and their decay was measured with a $\gamma$ detector.

\subsection{The cocktail beam and the targets}

A so-called cocktail beam $[12,58,59]$ consisting of ${ }^{18} \mathrm{O}^{4+}$ and ${ }^{50} \mathrm{Ti}^{11+}$ was developed using isotopically enriched metallic ${ }^{50} \mathrm{Ti}$ and gaseous ${ }^{18} \mathrm{O}_{2}$. The particles were extracted from the Lawrence Berkeley National Laboratory's (LBNL) Electron Cyclotron Resonance (ECR) ion source, injected into the 88-Inch Cyclotron and accelerated to about $4.6 \mathrm{MeV} / \mathrm{u}$. By varying the cyclotron frequency, either $83.6-\mathrm{MeV}^{18} \mathrm{O}^{4+}$ or $228.0-\mathrm{MeV}{ }^{50} \mathrm{Ti}^{11+}$ projectiles were extracted. They passed through a $\sim 45-\mu \mathrm{g} / \mathrm{cm}^{2}$ thick ${ }^{\text {nat }} \mathrm{C}$ vacuum window and a negligible amount of $\mathrm{He}$ before entering the target (backing). Isotopically enriched targets of ${ }^{74} \mathrm{Se},{ }^{116} \mathrm{Sn},{ }^{120} \mathrm{Sn}$, ${ }^{124} \mathrm{Sn}$, as well as ${ }^{\text {nat }} \mathrm{Ge}$, all in the elemental form, were used. They were produced by vacuum deposition from a resistively heated source. Table 1 lists the properties of the used targets along with the EVRs of interest produced in complete fusion reactions with the ${ }^{18} \mathrm{O}$ beams (targets \#1 and \#2) and ${ }^{50} \mathrm{Ti}$ beams (\#3 to \#6).

Hereafter, the targets are referred to according to their entry in column 1 in Table 1 . The energy loss of the beam through the various layers of matter (neglecting the He between the vacuum window and the target) was calculated with SRIM-2003 [60]. The resulting lab-frame beam energies in the center of the target were around $83 \mathrm{MeV}$ in the ${ }^{18} \mathrm{O}$ induced reactions and around $224 \mathrm{MeV}$ in the ${ }^{50} \mathrm{Ti}$-induced reactions. Typical beam intensities were $\sim 6 \times 10^{11} \mathrm{~s}^{-1}\left({ }^{18} \mathrm{O}\right)$ and $(1-2) \times 10^{11} \mathrm{~s}^{-1}\left({ }^{50} \mathrm{Ti}\right)$. Up to five targets were mounted on a slider that allowed for the desired target to be positioned in the path of the beam without opening the system.

\subsection{Physical preseparation in the BGS}

The desired products of the nuclear reactions were separated from the beam and the majority of the nuclear transfer products by the BGS which was filled with 0.7 mbar He. The magnetic rigidities of the reaction products (on which separation in the BGS is based) have been measured earlier and are given in [12]. The part of the experimental setup downstream from the BGS is depicted in Fig. 2.

The EVRs were guided to the focal plane area of the BGS, extracted from the separator through the Mylar RTC window (throughout the remainder of Sect. 2, items in italics refer to experimental equipment explicitly labeled in Fig. 2). In most experiments, the foil was $3.3 \mu \mathrm{m}$ thick. This allowed the Hf EVRs as well as the rather slow Zr EVRs to exit the BGS [12]. In the Hf experiments, an additional Mylar degrader foil of $5.8 \mu \mathrm{m}$ thickness was inserted in front of the window to reduce the kinetic energy of the Hf EVRs so that they were stopped inside the $R T C$. After passing through the $R T C$ window, the EVRs entered the RTC [15].

\subsection{The recoil transfer chamber and the gas flow system}

Two He (purity $\geq 99.999 \%$ ) streams were individually controlled with mass flow controllers (MKS Instruments Inc., type 1179A). A trap containing molecular sieve kept at ambient temperature was inserted into the gas supply line upstream of the mass flow controllers to remove the main fraction of the water from the gas. Each He stream was further dried by passing trough a liquid nitrogen trap. One of the two gas streams was passed through the hfa enrichment station located outside of the cave and then brought back into the cave. The enrichment station consisted of two bubblers containing $h f a$ and a bypass that were installed in parallel. The bubblers were placed in a temperature controlled water bath to control the amount of hfa that was added to the He. Periodically, 1-2 mL $h f a$ was added to the bubbler via the addition funnel allowing for a relatively constant $h f a$ volume without having to open the system.

Table 1. Targets used in this work. The last columns list key properties of the EVRs of interest.

\begin{tabular}{|c|c|c|c|c|c|c|c|}
\hline Target & Backing & Isotope & $\begin{array}{l}\text { Target thickness } \\
\qquad\left(\mu \mathrm{g} / \mathrm{cm}^{2}\right)\end{array}$ & Cover & $\begin{array}{l}\text { EVR of } \\
\text { interest }\end{array}$ & $\begin{array}{c}\text { Half-life } \\
\text { [57] }\end{array}$ & $\begin{array}{l}\text { Evaluated } \gamma \text {-line } \\
\quad(\mathrm{keV})[57]\end{array}$ \\
\hline \#1 & $45 \mu \mathrm{g} / \mathrm{cm}^{2} \mathrm{C}$ & ${ }^{\text {nat }} \mathrm{Ge}$ & 350 & - & ${ }^{85} \mathrm{Zr}$ & $7.86 \mathrm{~min}$ & 454.3 \\
\hline \#2 & $40 \mu \mathrm{g} / \mathrm{cm}^{2} \mathrm{C}$ & ${ }^{74} \mathrm{Se}$ & 384 & $50 \mu \mathrm{g} / \mathrm{cm}^{2} \mathrm{Au}$ & ${ }^{85} \mathrm{Zr}$ & $7.86 \mathrm{~min}$ & 454.3 \\
\hline \#3 & $45 \mu \mathrm{g} / \mathrm{cm}^{2} \mathrm{C}$ & ${ }^{116} \mathrm{Sn}$ & various, $250-478$ & - & ${ }^{162} \mathrm{Hf}$ & $37.6 \mathrm{~s}$ & 173.90 \\
\hline \#4 & $45 \mu \mathrm{g} / \mathrm{cm}^{2} \mathrm{C}$ & ${ }^{120} \mathrm{Sn}$ & two, $200 \& 300$ & - & ${ }^{165} \mathrm{Hf}$ & $76 s$ & 180.0 \\
\hline \#5 & $45 \mu \mathrm{g} / \mathrm{cm}^{2} \mathrm{C}$ & ${ }^{124} \mathrm{Sn}$ & 500 & - & ${ }^{169} \mathrm{Hf}$ & $3.24 \mathrm{~min}$ & 492.86 \\
\hline \#6 & - & ${ }^{124} \mathrm{Sn}$ & 586 & - & ${ }^{169} \mathrm{Hf}$ & $3.24 \mathrm{~min}$ & 492.86 \\
\hline
\end{tabular}




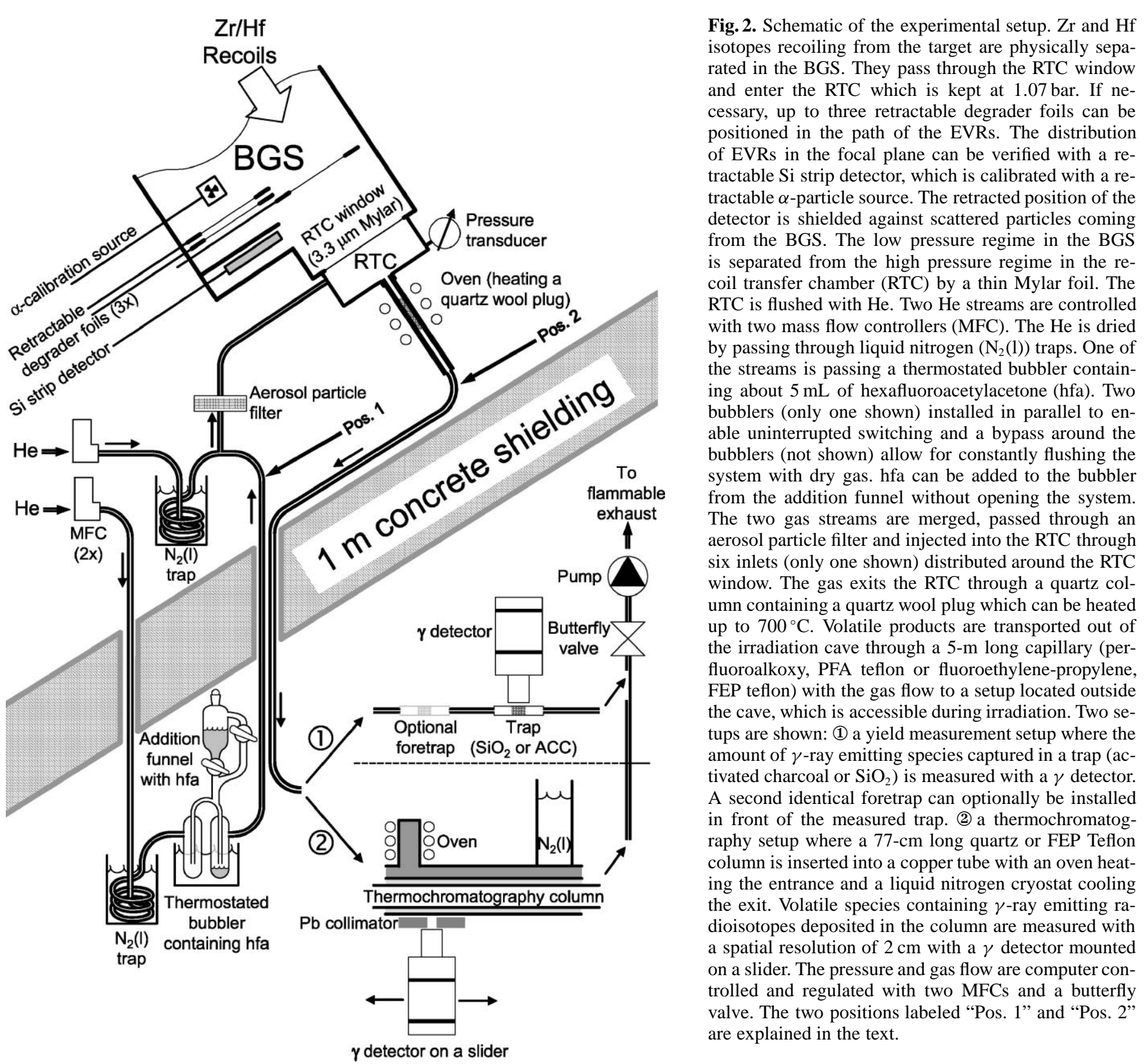

The $h f a(98+\%$ purity) was purchased from various suppliers and distilled before use. The hfa-enriched He stream was then merged with the second gas stream. This system allowed large variations of the gas flow rates without severely affecting the hfa consumption rate and provided freedom in the choice of hfa content in the gas stream. For some experiments, a heatable (up to $550^{\circ} \mathrm{C}$ ) quartz wool plug was installed in the position labeled "Pos. 1" in Fig. 2. This served to determine the decomposition temperature of hfa, see Sect. 3.1.3. The merged He stream was then passed through an aerosol particle filter to prevent the transport of radionuclides attached to aerosol particles and then fed into the RTC, a $322-\mathrm{cm}^{3}$ large volume kept at a pressure of about 1.07 bar. Typical gas flow rates were $650 \mathrm{~mL} / \mathrm{min}$ for the stream that was passing the bubbler and $650-1450 \mathrm{~mL} / \mathrm{min}$ for the other stream, resulting in total He flow rates of about $1300-2100 \mathrm{~mL} / \mathrm{min}$. The hfa concentration in the carrier gas was determined to be $2.1 \mathrm{~mol}-\%$ (with an estimated uncertainty of a factor of two) from the He flow rate and the consumption rate of the $h f a$. The gas exited through the center of the $R T C$ back-plate through a $36-\mathrm{cm}$ long quartz column (i.d. $4 \mathrm{~mm}$ ). A quartz wool plug that could be heated by a resistance oven to about $700{ }^{\circ} \mathrm{C}$ was located $\sim 8-10 \mathrm{~cm}$ downstream of the entrance and kept in place by two indentations in the quartz column. Cooling jackets on both sides of the oven kept the temperatures of the RTC back plate and the exit of the quartz column at $<50{ }^{\circ} \mathrm{C}$. At the exit of the column, at the position labeled "Pos. 2" in Fig. 2, activated charcoal (ACC) traps as described in Sect. 2.5 could be installed to collect species that were transported to the exit of the quartz column. The traps were retrieved after the end of the irradiation and counted off-line. In most of the experiments, however, the gas was transported in either a perfluoroalkoxy (PFA) Teflon or a fluorinated ethylene propylene (FEP) Teflon capillary (about $5 \mathrm{~m}$ long, i.d. $1.6 \mathrm{~mm}$ ) to an experimental area that was accessible during the irradiation as retention of the chemical species of interest in the capillary was found to be negligible at temperatures $>30^{\circ} \mathrm{C}$, see also Sect. 3.4. Those capillaries together with two ex- 
ternal pumping loops connected to refrigerated and heating circulators were installed inside of a thermal insulation on a length of about $4 \mathrm{~m}$. The temperature of the capillaries could thus be set to any desired temperature between $0{ }^{\circ} \mathrm{C}$ and $+90^{\circ} \mathrm{C}$, allowing them to serve as isothermal chromatography columns. The setup ensured the temperature in the tubes to be constant to within less than $1{ }^{\circ} \mathrm{C}$ along the whole $4 \mathrm{~m}$.

The remainder of the capillaries, i.e., $50 \mathrm{~cm}$ on each side of the isothermal section, were heated with heating tape to temperatures higher than the one of the isothermal section to ensure negligible retention in this part compared to the isothermal section. The pressure inside the RTC was measured with a pressure transducer (MKS Instruments Inc., type $722 \mathrm{~A}$ ) and held at a preset value with a butterfly-valve (MKS Instruments Inc., type 153). Both mass flow controllers, the pressure transducer, and the butterfly valve were controlled by a MKS Instruments Inc. type $186 \mathrm{~B}$ process controller.

\subsection{The catcher foil holder}

The standard RTC back plate could be exchanged for a different one containing a so-called catcher foil holder, which was placed a few $\mathrm{mm}$ behind the RTC window and covered its whole area. Catcher foils of $25-\mu \mathrm{m}$ thick household $\mathrm{Al}$ foil were attached to the holder. All nuclear reaction products (except the scattered ${ }^{18} \mathrm{O}$ beam) entering the $R T C$ (which was kept at a pressure below 0.1 bar for these experiments) were stopped inside the catcher foils, as was predicted by SRIM-2003 [60] calculations and confirmed experimentally. These reaction products could be brought to the counting area outside the cave within about $90 \mathrm{~s}$ after the end of bombardment. Thus, absolute quantities of the isotopes of interest entering the $R T C$ could be measured even for the rather short-lived ${ }^{162} \mathrm{Hf}\left(T_{1 / 2}=37.6 \mathrm{~s}\right)$.

\subsection{The yield measurement setup}

The amount of $\mathrm{Hf}$ or $\mathrm{Zr}$ isotopes that was transported was determined using two different kinds of traps. To measure the total amount of transported species, traps consisting of about $5 \mathrm{~cm}$ long pieces of plastic tubing (i.d. $4.8 \mathrm{~mm}$ ) filled with ACC (20-40 mesh grain size) were used. The ACC was kept in place by quartz wool plugs on both sides and that in turn was kept in place by tubing with a smaller diameter that was glued into the larger tubes with a two component glue. The tube was filled with ACC on a length of about $15 \mathrm{~mm}$, corresponding to about $80 \mathrm{mg}$ of ACC. In other measurements, radioactive species that were adsorbed to aerosol particles and transported with the gas flow in this form were selectively measured. Traps for these experiments consisted of PFA tubes that were filled with quartz $\left(\mathrm{SiO}_{2}\right)$ wool which was previously deactivated at $900{ }^{\circ} \mathrm{C}$ in an oxygen containing atmosphere. They are referred to as $\mathrm{SiO}_{2}$ traps hereafter.

The traps were connected to the FEP or PFA transport lines with BOLA connectors (Bohlender GmbH, Grünsfeld, Germany) made from polytetrafluoroethylene (PTFE) Teflon.
The Al catcher foils used to determine the amount of activity entering the $R T C$ (see Sect. 2.4) were folded up and placed in an identical piece of PFA tubing to ensure an identical counting geometry and thus allow a direct comparison of the amount of radioactive species with the traps measurements.

The traps were installed directly at the exit of the quartz column located at the exit of the RTC ("Pos. 2" in Fig. 2) or at the end of the $\sim 5$-m long capillaries, as shown in Fig. 2. They were either counted off-line (those from "Pos. 2") or on-line (those installed outside the cave). A holder was built to ensure reproducible geometry for all measurements.

A HPGe $\gamma$ detector (Ortec, Oak Ridge, TN, model GMX$23195-\mathrm{S}$ ) with an efficiency of $23 \%$ relative to a $3 " \times 3 "$ NaI cylinder detector with standard NIM electronics modules was used for all $\gamma$ spectroscopic measurements. In addition to the $\gamma$-lines of the EVRs of interest mentioned in the last column of Table 1 , the following $\gamma$-lines [57] were used in the analysis of the experiments: ${ }^{86 \mathrm{~m}} \mathrm{Y}$ (48 min): $208.1 \mathrm{keV} ;{ }^{87 \mathrm{~m}} \mathrm{Zr}(14.0 \mathrm{~s}): 134.8 \mathrm{keV}, 200.95 \mathrm{keV} ;{ }^{87 \mathrm{~m}, \mathrm{~g}} \mathrm{Nb}$ (m: $3.7 \mathrm{~min} ; \mathrm{g}: 2.6 \mathrm{~min}$ ): $201.0 \mathrm{keV} ;{ }^{88 \mathrm{~m}, \mathrm{~g}} \mathrm{Nb}$ (m: $7.8 \mathrm{~min}$; g: $14.5 \mathrm{~min}): 399.4 \mathrm{keV}, 1057.1 \mathrm{keV}, 1082.6 \mathrm{keV} ;{ }^{88} \mathrm{Mo}$ (8.0 $\mathrm{min}): 170.5 \mathrm{keV}$.

\subsection{The thermochromatography setup}

Thermochromatography [56] is a well established technique that has proven successful in the investigation of single atoms (see, e.g., [61]) including those of the heaviest elements (see, e.g., $[3,10])$. In this method, a negative temperature gradient is established along an open chromatography column. Depending on the interaction strength of the species with the column material, deposition of the species occurs at a specific temperature corresponding to a specific position. In our case, the distribution of the species inside the column was determined with $\gamma$-spectroscopy.

A 77-cm long quartz or FEP Teflon thermochromatography column (i.d. $4 \mathrm{~mm}$ ) was installed in a thin-walled copper tube which was welded into a $1.9 \times 3.8 \mathrm{~cm}^{2}$ copper bar (shown in gray in Fig. 2). An oven was installed on the entrance side of the tube while a container for liquid nitrogen was installed on a $2.5 \times 2.5 \mathrm{~cm}^{2}$ copper bar attached to the cold end of the column. By varying the distance of the container from the chromatography column, the lowest temperature of the temperature gradient could be adjusted. It was typically mounted at a distance of about $30 \mathrm{~cm}$ and in this way, a longitudinal negative temperature gradient from $\sim+50{ }^{\circ} \mathrm{C}$ to $\sim-40^{\circ} \mathrm{C}$ was established along the thermochromatography column. Lower temperatures led to the deposition of macroamounts of hfa. The front side of the copper tube was kept clear to be accessible for $\gamma$-spectroscopy, which allowed on-line measurement of the distribution of the $\mathrm{Zr}$ and Hf isotopes in the column. The same HPGe $\gamma$ detector as described in Sect. 2.5 was used. A $20-\mathrm{mm}$ thick lead collimator with a $1 \mathrm{~cm}$ high $\times$ $2 \mathrm{~cm}$ wide open window was placed in front of the detector to allow for a spatial resolution of $2 \mathrm{~cm}$. The detector and the collimator were placed on a cart that was sliding along the column. An ACC trap of the same type as described in Sect. 2.5 (not shown in Fig. 2) was installed after the exit of the chromatography column to catch potential species that 
were passing the chromatography column without being retained. The trap was placed in an identical piece of copper tubing as the quartz column. This ensured the same counting geometry and thus allowed for absolute quantification of the radioisotopes that passed the column.

\section{Results}

Different experiment series were conducted mainly i) to investigate the formation of volatile species in the chosen chemical system and to find the optimum experimental parameters for the reactions to be as fast as possible, ii) to study the thermal stability of the formed volatile species with the goal of determining the chemical species through comparison with data available from the study of macroamounts, and iii) to study their interaction with FEP Teflon and quartz in gas chromatography experiments. Table 2 summarizes the experiments described in the following sections.

\subsection{Yield $v s$. reaction temperature}

Initially, experiments were performed to ensure that the hfa content of the carrier gas remained low enough that no formation of aerosol particles occurred. For this, the temperature of the $\mathrm{hfa}$ was varied between $15^{\circ} \mathrm{C}$ and $60^{\circ} \mathrm{C}$ and the yield of ${ }^{162} \mathrm{Hf}$ (produced with target \#3, thickness $352 \mu \mathrm{g} / \mathrm{cm}^{2}$ ) was measured i) in an ACC trap and ii) in an ACC trap mounted behind a $\mathrm{SiO}_{2}$ trap, which was installed to selectively retain aerosol particles, resulting in the ACC trap collecting only volatile species that passed the $\mathrm{SiO}_{2}$ trap. The reaction temperature, $T_{R}$, of the quartz wool plug at the RTC exit, which was set by the oven heating it, was $62{ }^{\circ} \mathrm{C}$. The direct $\mathrm{He}$ gas flow rate was $2050 \mathrm{~mL} / \mathrm{min}$ and the flow rate of He through the bubbler was $650 \mathrm{~mL} / \mathrm{min}$. Up to hfa temperatures of $\sim 50{ }^{\circ} \mathrm{C}$, the same yield of ${ }^{162} \mathrm{Hf}$ was measured regardless of whether a $\mathrm{SiO}_{2}$ foretrap was installed or not; at temperatures of $60^{\circ} \mathrm{C}$, significantly more ${ }^{162} \mathrm{Hf}$ was measured in the ACC trap with no $\mathrm{SiO}_{2}$ foretrap in front than in the ACC trap sensitive only to volatile species, indicating, that aerosol transport occurred at that hfa temperature, likely due to the formation of hfa aerosol particles due to the high hfa concentration.

Absolute overall yields of ${ }^{162,165,169} \mathrm{Hf}$ and ${ }^{85} \mathrm{Zr}$ were measured over a broad range of $T_{\mathrm{R}}$. Two series of measurements were performed: one with gas flow rates of $1300 \mathrm{~mL} / \mathrm{min}(650 \mathrm{~mL} / \mathrm{min}$ through the hfa bubbler, $650 \mathrm{~mL} / \mathrm{min}$ directly passed into the RTC) with the hfa kept at $15^{\circ} \mathrm{C}$ (hereafter these are referred to as low-flowrate experiments), and another one with gas flow rates of $2100 \mathrm{~mL} / \mathrm{min}(650 \mathrm{~mL} / \mathrm{min} / 1450 \mathrm{~mL} / \mathrm{min})$ with the hfa kept at $40{ }^{\circ} \mathrm{C}$ (high-flow-rate experiments). Experiments were extended over a $T_{\mathrm{R}}$ range of $30-660^{\circ} \mathrm{C}$.

One individual measurement looked as follows: the carrier gas was switched to pass through the hfa about one minute before the start of the irradiation to allow the whole system to be equilibrated. At time $t=0$, the beam was switched on. In experiments where the traps were installed after the capillary, the acquisition of a $\gamma$ spectrum was started at $t=90 \mathrm{~s}$ and the sample was counted for $300 \mathrm{~s}$ (on-line experiments). The beam was stopped at $t=720 \mathrm{~s}$ and in experiments with comparatively long-lived ${ }^{85} \mathrm{Zr}$ and ${ }^{169} \mathrm{Hf}$, a second measurement of the same trap was started at $\mathrm{t}=900 \mathrm{~s}$. This measurement lasted $600 \mathrm{~s}$ (off-line experiments). Traps installed at "Pos. 2" in Fig. 2 were only counted off-line. For each experiment with an ACC trap, a fresh one was used. The beam intensity was usually measured before and after each irradiation. Over the whole temperature range, the total amount of transported radionuclides was measured by using an ACC trap. In low-flow-rate experiments with $\mathrm{Hf}$ as well as in high-flow-rate experiments with $\mathrm{Zr}$ and $\mathrm{Hf}$ above $\sim 200^{\circ} \mathrm{C}$, two additional kinds of measurements were performed: (i) $\mathrm{a} \mathrm{SiO}_{2}$ trap was used instead of the ACC trap to measure radionuclides attached to aerosol particles, and (ii) an ACC trap that was mounted behind a $\mathrm{SiO}_{2}$ trap (optional foretrap in Fig. 2) was used to measure radionuclides that were transported in the form of volatile species.

The capacity of the ACC traps was found to be sufficient for $\sim 15$ min long runs. Tests in which two traps were placed in series showed that using an already used trap in a second experiment resulted in a breakthrough into the second trap, but that they retained $100 \%$ of the transported species during the course of one individual measurement conducted in both, the on-line as well as the off-line time pattern.

The data analysis was performed as follows: the peak areas were determined using standard $\gamma$-spectra analysis software. The peak areas were corrected for dead time losses and variations in beam intensity. Every measurement was normalized to a catcher foil measurement taken in the same experiment series. A few measurements had slight offsets in the timing pattern (e.g., when a measurement was erroneously started a few seconds too late), the effects of which were corrected using the half-lives given in Sect. 2. A specific point in time was defined and the activities of the samples at that time were calculated. For off-line sam-

Table 2. Summary of the performed experiments. Abbreviations and definitions are explained in the text.

\begin{tabular}{|c|c|c|c|c|}
\hline \multirow{2}{*}{$\begin{array}{l}\text { Nuclear } \\
\text { reaction }\end{array}$} & \multirow{2}{*}{$\begin{array}{l}\text { EVR of } \\
\text { interest }\end{array}$} & \multicolumn{2}{|c|}{ Yield $v s$. reaction temperature } & \multirow{2}{*}{$\begin{array}{l}\text { Additional } \\
\text { experiments }\end{array}$} \\
\hline & & Low-flow-regime & High-flow-regime & \\
\hline $\begin{array}{l}{ }^{18} \mathrm{O}+{ }^{\mathrm{nat}} \mathrm{Ge} \\
{ }^{18} \mathrm{O}+{ }^{74} \mathrm{Se}\end{array}$ & ${ }^{85} \mathrm{Zr}$ & on-line + off-line & on-line + off-line & \\
\hline${ }^{50} \mathrm{Ti}+{ }^{116} \mathrm{Sn}$ & ${ }^{162} \mathrm{Hf}$ & on-line & on-line & Isothermal (on PFA) \\
\hline${ }^{50} \mathrm{Ti}+{ }^{120} \mathrm{Sn}$ & ${ }^{165} \mathrm{Hf}$ & on-line & on-line & $T_{1 / 2}$ of ${ }^{165} \mathrm{Hf}$ \\
\hline${ }^{50} \mathrm{Ti}+{ }^{124} \mathrm{Sn}$ & ${ }^{169} \mathrm{Hf}$ & on-line + off-line & on-line + off-line & $\begin{array}{l}\text { search for } \mathrm{Hf}(\mathrm{tfa})_{4} \\
\mathrm{TC}(\text { on quartz \& FEP) }\end{array}$ \\
\hline
\end{tabular}


ples, the radioactive decay law was used. For on-line samples, in addition, growth during irradiation was considered. Normalizing these activities to the respective catcher foil activities allowed determination of the absolute yield of the radioisotopes. From the $\sim 140$ measurements with an ACC trap, four were disregarded as outliers in the data analysis as they were significantly deviating from the trends established by the rest of the data set, for reasons that are not clear.

Periodically, experiments with pure He gas (i.e., without addition of hfa) were preformed to check the integrity of the system. Hf or $\mathrm{Zr}$ were not detected behind the RTC-oven in any of these experiments.

\subsubsection{Low flow rate regime}

Initial experiments were conducted in the low-flow-rate regime with ${ }^{85} \mathrm{Zr}$ and ${ }^{169} \mathrm{Hf}$ at $T_{\mathrm{R}}$ up to around $300{ }^{\circ} \mathrm{C}$ and in a second series up to around $600^{\circ} \mathrm{C}$. The measured absolute yields are shown in Fig. 3. In the following figures, solid symbols represent results obtained in the off-line time pattern, open symbols such obtained in the on-line time pattern. Different symbols indicate different isotopes. ${ }^{85} \mathrm{Zr}$ (squares) and ${ }^{169} \mathrm{Hf}$ (diamonds) were measured in both time patterns, ${ }^{165} \mathrm{Hf}$ (circles) and ${ }^{162} \mathrm{Hf}$ (stars), due to their short half-lives, only in the on-line pattern. As shown in Fig. 3, the off-line data for $7.86-\mathrm{min}{ }^{85} \mathrm{Zr}$ and 3.24-min ${ }^{169} \mathrm{Hf}$ exhibited different behavior. While the yield of ${ }^{85} \mathrm{Zr}$ was constant and high over the whole temperature range, the ${ }^{169} \mathrm{Hf}$ yield was similar at temperatures up to $100^{\circ} \mathrm{C}$, then decreased significantly and reached the high ${ }^{85} \mathrm{Zr}$ values again at temperatures above $\sim 250{ }^{\circ} \mathrm{C}$. In subsequent on-line studies (open symbols), also ${ }^{85} \mathrm{Zr}$ (open squares) showed a reduced yield at temperatures between $\sim 100$ and $\sim 250{ }^{\circ} \mathrm{C}$, and for ${ }^{169} \mathrm{Hf}$ (open diamonds) the dip was even more pronounced.

The same low-flow-rate experiments were also conducted with even shorter-lived isotopes. These were restricted to $\mathrm{Hf}\left({ }^{162} \mathrm{Hf}\right.$ and $\left.{ }^{165} \mathrm{Hf}\right)$ due to the lack of suitable $\mathrm{Zr}$ isotopes. ${ }^{85 \mathrm{~m}} \mathrm{Zr}(10.9 \mathrm{~s})$ has never been observed in our

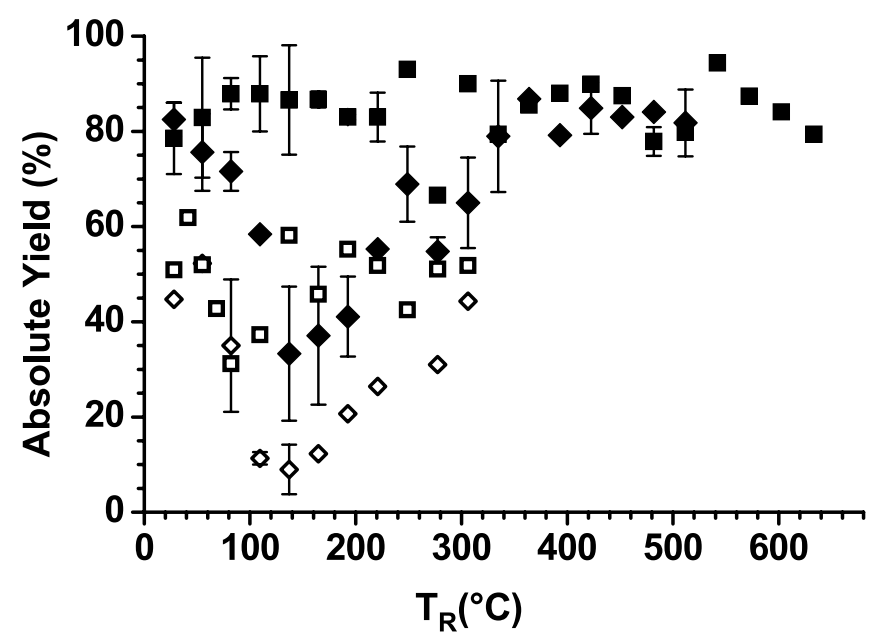

Fig. 3. Absolute yields of ${ }^{85} \mathrm{Zr}$ (squares) and ${ }^{169} \mathrm{Hf}$ (diamonds) obtained in the low-flow-rate regime in the off-line (solid symbols) and on-line (open symbols) time pattern.

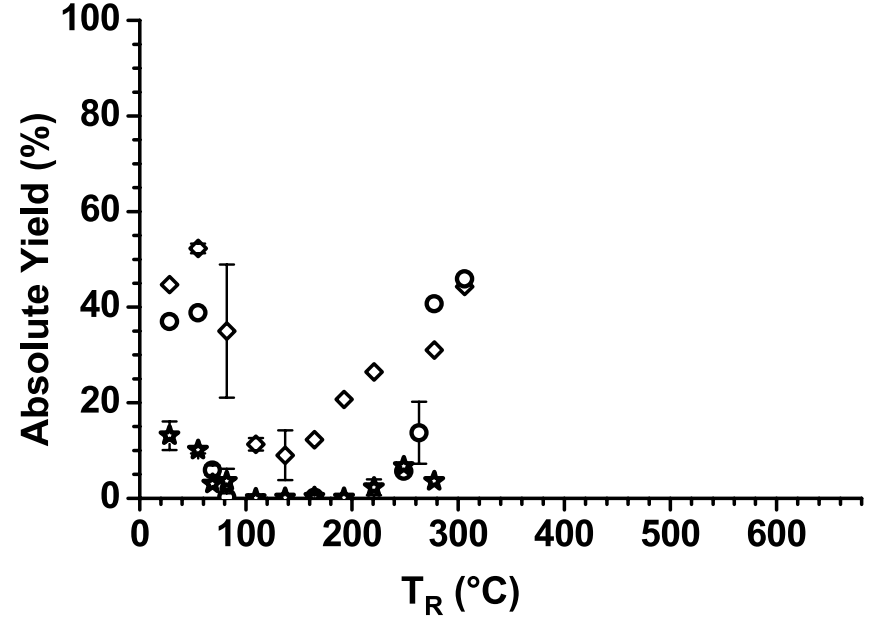

Fig. 4. Absolute yields of ${ }^{169} \mathrm{Hf}$ (diamonds), ${ }^{165} \mathrm{Hf}$ (circles), and ${ }^{162} \mathrm{Hf}$ (stars) obtained in the low-flow-rate regime in the on-line time pattern. The ${ }^{169} \mathrm{Hf}$ data are the same as in Fig. 3 and are included to facilitate comparison of Figs. 3 and 4.

experiments. Some of the samples taken in the on-line pattern were also counted in the off-line pattern. Comparison of these peak areas with those from catcher foils allows determining absolute yields, also for $37.6-\mathrm{s}{ }^{162} \mathrm{Hf}$. These results are shown in Fig. 4. For better comparison, the ${ }^{169} \mathrm{Hf}$ (online) data from Fig. 3 are included in Fig. 4 as well.

These studies covered a temperature range up to $\sim$ $300{ }^{\circ} \mathrm{C}$ because decomposition of the complexes at higher temperatures was expected. However, Figs. 3 and 4 indicate that the yield was strongly increasing with increasing temperature once the minimum between $\sim 100^{\circ} \mathrm{C}$ and $\sim 250^{\circ} \mathrm{C}$ is exceeded. Not unexpectedly, further tests showed an increasing yield with increasing gas-flow rate, so a second data set was acquired in the high-flow-rate regime.

\subsubsection{High flow rate regime}

For the high-flow-rate regime, the range of $T_{\mathrm{R}}$ was increased and covered room temperature up to $\sim 600^{\circ} \mathrm{C}$. For better readability, the results are shown in two separate Figs. 5 and 6. The symbols are the same as in Figs. 3 and 4.

Surprisingly high yields were observed at temperatures where substantial thermal decomposition of the complexes was expected. One possible explanation would be that the macroamounts of hfa were thermally decomposed and that the decomposition products formed aerosol particles that would lead to a non-chemically selective transport, similar to a gas-jet. To investigate this, additional experiments were performed where $\mathrm{a} \mathrm{SiO}_{2}$ trap was placed in front of the ACC trap ("optional foretrap" in Fig. 2) to collect aerosol particles. In separate experiments covering a temperature range of $200-610^{\circ} \mathrm{C}$ the activity deposited on the foretrap as well as on the ACC traps was measured. Fig. 7 shows the results of the $\mathrm{SiO}_{2}$ traps. An independent possibility to check for non-chemically selective transport is offered by the investigation of ${ }^{86 \mathrm{~m}} \mathrm{Y}$. This isotope in its isomeric state is produced in p $x$ n exit channels in the ${ }^{18} \mathrm{O}+{ }^{\text {nat }} \mathrm{Ge}$ and ${ }^{18} \mathrm{O}+{ }^{74} \mathrm{Se}$ reactions (see Fig. 3 in [12]) and easily detectable. Note that the decay of ${ }^{86} \mathrm{Zr}$ bypasses this state. As the transport of $\mathrm{Y}$ in the form of volatile compounds has not been observed 


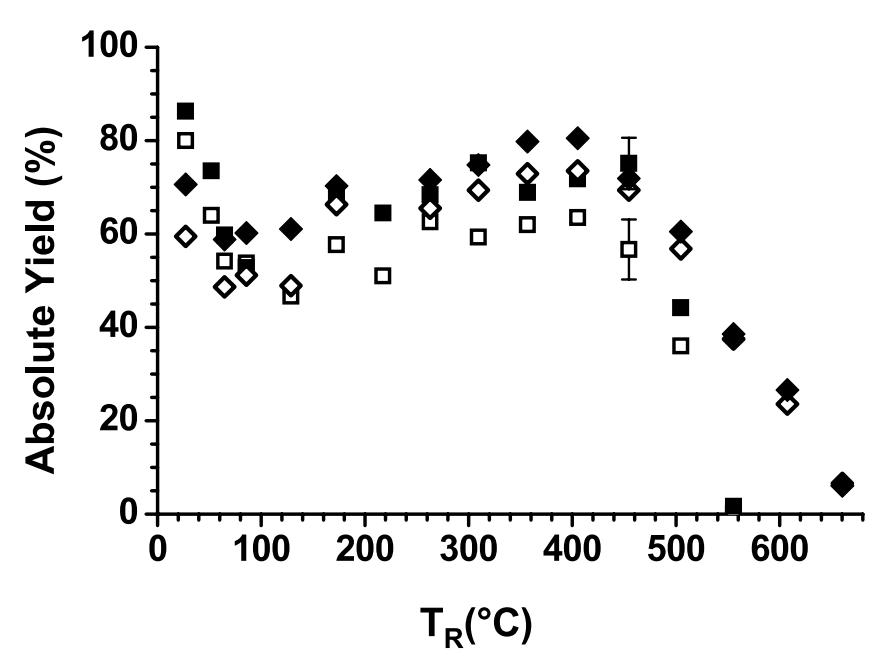

Fig. 5. Absolute yields of ${ }^{85} \mathrm{Zr}$ (squares) and ${ }^{169} \mathrm{Hf}$ (diamonds) obtained in the high-flow-rate regime in the off-line (solid symbols) and on-line (open symbols) time pattern.

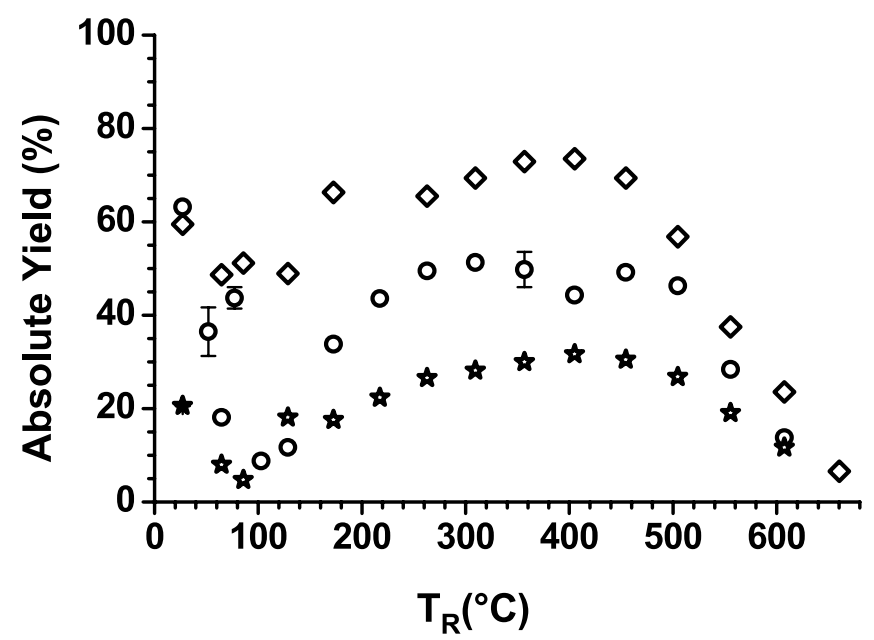

Fig. 6. Absolute yields of ${ }^{169} \mathrm{Hf}$ (diamonds), ${ }^{165} \mathrm{Hf}$ (circles), and ${ }^{162} \mathrm{Hf}$ (stars) obtained in the high-flow-rate regime in the on-line time pattern. The ${ }^{169} \mathrm{Hf}$ data are the same as in Fig. 5 and are included to facilitate comparison of Figs. 5 and 6.

in our experiments, the presence of ${ }^{86 \mathrm{~m}} \mathrm{Y}$ would indicate aerosol-transport. Accordingly, all spectra of experiments where ${ }^{85} \mathrm{Zr}$ was investigated were inspected for the presence of the $208 \mathrm{keV} \gamma$-line. No ${ }^{86 \mathrm{~m}} \mathrm{Y}$ was found in the following samples:

- all low-flow-rate off-line samples up to $200{ }^{\circ} \mathrm{C}$,

- all low-flow rate on-line samples (which extended up to $300{ }^{\circ} \mathrm{C}$ ),

- all high-flow rate off-line samples up to $220^{\circ} \mathrm{C}$,

- all high-flow rate off-line samples of an ACC trap mounted behind a $\mathrm{SiO}_{2}$ foretrap, also at temperatures $>550{ }^{\circ} \mathrm{C}$,

- all high-flow-rate on-line samples up to $250{ }^{\circ} \mathrm{C}$,

- all high-flow rate on-line samples of an ACC trap mounted behind a $\mathrm{SiO}_{2}$ foretrap, also at temperatures $>550{ }^{\circ} \mathrm{C}$.

However, in high-flow-rate experiments above $220^{\circ} \mathrm{C}$ (offline) and above $250{ }^{\circ} \mathrm{C}$ (on-line), ${ }^{86 \mathrm{~m}} \mathrm{Y}$ was found in ACC traps that were used to collect all transported species and especially in $\mathrm{SiO}_{2}$ traps used as foretraps. The yields of ${ }^{86 \mathrm{~m}} \mathrm{Y}$

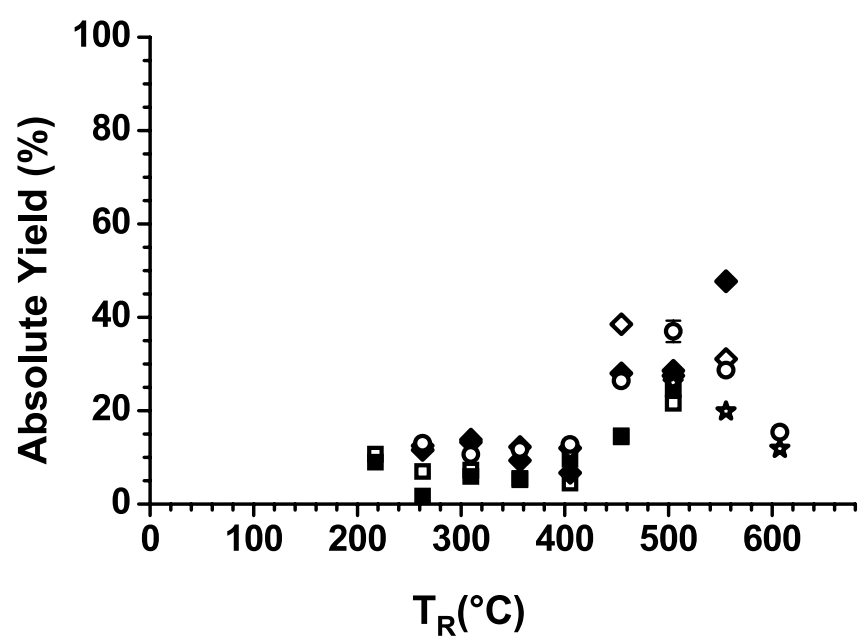

Fig. 7. Absolute yields of ${ }^{85} \mathrm{Zr}$ (squares), ${ }^{169} \mathrm{Hf}$ (diamonds), ${ }^{165} \mathrm{Hf}$ (circles), and ${ }^{162} \mathrm{Hf}$ (stars) found in $\mathrm{SiO}_{2}$ foretraps obtained in the high-flow-rate regime in the off-line (solid symbols) and on-line (open symbols) time pattern.

as a function of $T_{\mathrm{R}}$ followed closely the trend of $\mathrm{Zr}$ and $\mathrm{Hf}$ isotopes found in the $\mathrm{SiO}_{2}$ foretraps in the respective samples, which is shown in Fig. 7 as obtained in high-flow rate experiments in both, the on-line and off-line time pattern.

The sum of the activities in the $\mathrm{SiO}_{2}$ foretraps and the ACC trap behind the foretraps agreed with the activities obtained in experiments with the ACC trap without a foretrap (see Figs. 5 and 6) within the experimental uncertainties.

The ${ }^{86 \mathrm{~m}} \mathrm{Y}$ results indicate that at temperatures in the range of $250-350{ }^{\circ} \mathrm{C}$, the dominant form of transport still seems to be chemically selective transport, but at higher temperatures, all ${ }^{85} \mathrm{Zr}$ found in the ACC as well as in the $\mathrm{SiO}_{2}$ traps can be explained by assuming that it was transported attached to aerosol particles. Therefore, from both, the ${ }^{86 \mathrm{~m}} \mathrm{Y}$ as well as the $\mathrm{SiO}_{2}$ foretrap experiments, we conclude that aerosol transport is not the dominant form of transport at temperatures below $\sim 350-400{ }^{\circ} \mathrm{C}$. This indicates that hfa decomposes at around $350-400{ }^{\circ} \mathrm{C}$, a finding in agreement with the known thermal stability of hfa: Bassett et al. report that there is no indication for thermal decomposition at temperatures up to $320^{\circ} \mathrm{C}$ [62], Droes et al. report observations that point to decomposition at temperatures $\geq 425^{\circ} \mathrm{C}$ [63], and Russell et al. describe photolysis experiments conducted at laser powers that correspond to temperatures of $477^{\circ} \mathrm{C}$ and $527^{\circ} \mathrm{C}$ and observed decomposition of hfa [64]. From the $\mathrm{SiO}_{2}$ foretrap data (which are of higher quality i) due to better counting statistics than the ${ }^{86 \mathrm{~m}} \mathrm{Y}$ ones and ii) because they cover ${ }^{85} \mathrm{Zr}$ as well as all three studied Hf isotopes) the absolute yield of $\mathrm{Zr}$ and $\mathrm{Hf}$ transported in the form of a volatile species, i.e., corrected for aerosol particle transport based on the data shown in Fig. 7, can be obtained. The results are displayed in Figs. 8 and 9, together with the data from Figs. 5 and 6 for the temperature region below $200{ }^{\circ} \mathrm{C}$, where formation of aerosol particles was shown to be negligible (see Fig. 7). Two outlying data points for ${ }^{169} \mathrm{Hf}$ (off-line time pattern) have been omitted in Fig. 8. The reason for the very large deviation from the trend established by the other data points is probably related to foretraps which did not work as efficient aerosol filters in these two runs. 


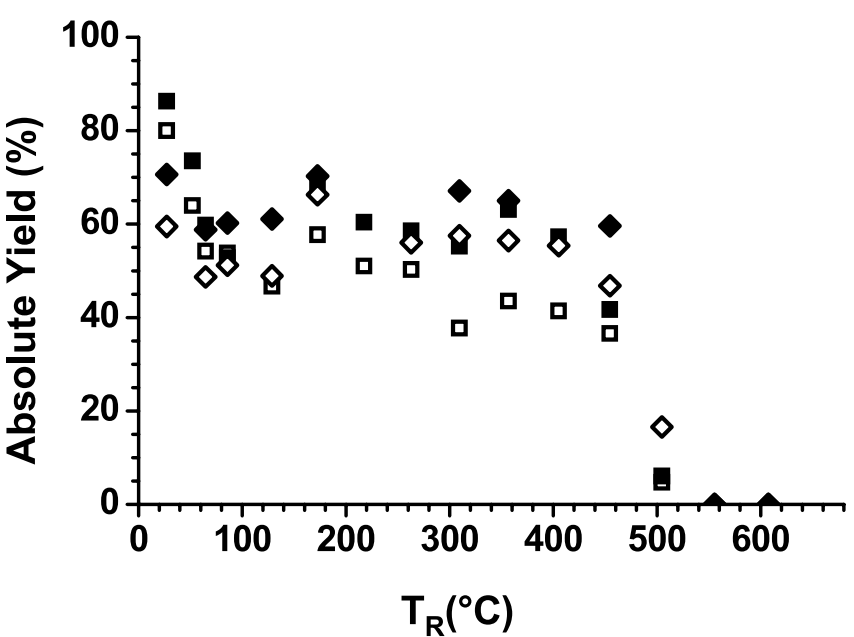

Fig. 8. Same as Fig. 5, but corrected for aerosol transport.

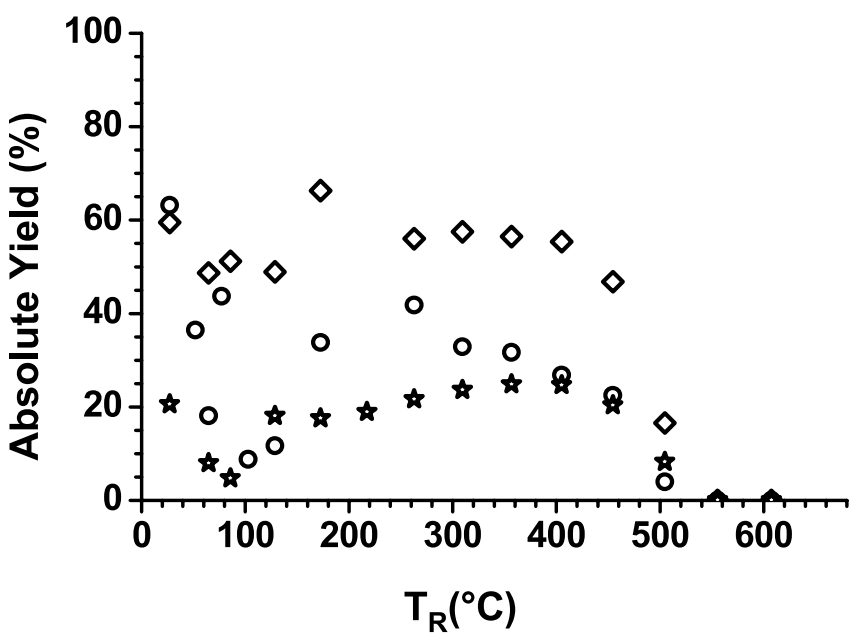

Fig. 9. Same as Fig. 6, but corrected for aerosol transport.

\subsubsection{Decomposition of hfa $v s$. decomposition of $\mathrm{Zr} / \mathrm{Hf}$ complexes}

The yield of chemically transported volatile $\mathrm{Zr}$ and $\mathrm{Hf}$ complexes decreased sharply at temperatures above $\sim 450{ }^{\circ} \mathrm{C}$, see Figs. 8 and 9. To elucidate whether i) the free ligand, i.e., hfa, or ii) the formed volatile complexes decomposed at these temperatures, additional measurements were performed. A quartz column with a heatable (up to $550^{\circ} \mathrm{C}$ ) quartz wool plug was installed at the position labeled with "Pos. 1" in Fig. 2. At high temperatures, hfa decomposes, and the non-volatile decomposition products (which form aerosol particles) are retained on the aerosol filter installed between the oven and the inlet into the RTC, see Fig. 2. The experiments were conducted in the low-flow-rate regime in the off-line time pattern. The $T_{\mathrm{R}}$ was set to $28^{\circ} \mathrm{C}$, where significant transport of all isotopes was observed, see Fig. 3. Experiments were performed with target \#1 and \#6 and the yields of ${ }^{85} \mathrm{Zr}$ and ${ }^{169} \mathrm{Hf}$ as a function of the temperature of this additional oven were measured. The yield was the same as shown in Fig. 3, i.e., around $80 \%$, as long as the temperature remained below $\sim 350{ }^{\circ} \mathrm{C}$. At higher temperatures, the yields of both isotopes dropped equally and were below $20 \%$ at temperatures above $\sim 400{ }^{\circ} \mathrm{C}$. Apparently, at temperatures
$>350{ }^{\circ} \mathrm{C}$, hfa decomposition sets in and is complete at temperatures $>400^{\circ} \mathrm{C}$.

\subsubsection{Behavior of $\mathrm{Nb}$ and Mo in the hfa system}

For some of the experiments in the low-flow-rate regime at $T_{\mathrm{R}}=42{ }^{\circ} \mathrm{C}$ with $\mathrm{Zr}$, target \#1 $\left({ }^{\text {nat }} \mathrm{Ge}\right.$ ) was replaced by target \#2 $\left({ }^{74} \mathrm{Se}\right)$. Inspection of a $\gamma$-spectrum, which was obtained in separate experiments, in which activity produced in this reaction was transported by a gas-jet to an ACC trap (Fig. 3b in [12]) reveals that short-lived $\mathrm{Nb}$ isotopes (mainly ${ }^{87 \mathrm{~m}, \mathrm{~g}} \mathrm{Nb}$ and ${ }^{88 \mathrm{~m}, \mathrm{~g}} \mathrm{Nb}$ ) are abundantly produced in this reaction in $\mathrm{p} x \mathrm{n}$ exit channels. A small peak of the $x \mathrm{n}$ evaporation product ${ }^{88} \mathrm{Mo}$ at $170.5 \mathrm{keV}$ is visible as well. A specific measurement with the ${ }^{74}$ Se target was therefore performed, and the yield of ${ }^{85} \mathrm{Zr}$ was $82.5 \%$, i.e., comparable to that obtained with the ${ }^{\text {nat }} \mathrm{Ge}$ target, and that of $\mathrm{Nb}$ (based on the evaluation of five $\gamma$-lines from ${ }^{87 \mathrm{~m}, \mathrm{~g}} \mathrm{Nb}$ and $\left.{ }^{88 \mathrm{~m}, \mathrm{~g}} \mathrm{Nb}\right)$ was $(6 \pm 1) \%$. The peak of ${ }^{88} \mathrm{Mo}$ was visible in the catcher foil measurement but not in the spectrum from the ACC trap, and an upper limit of $25 \%$ is obtained. This relatively large upper limit is a result of the weak ${ }^{88} \mathrm{Mo} \gamma$-line and is in line with earlier observations [12] that the ${ }^{18} \mathrm{O}+{ }^{74} \mathrm{Se}$ reaction is not well suited for the production of this lighter homolog of seaborgium $(\mathrm{Sg}$, $Z=106)$.

\subsubsection{Test experiments with trifluoroacetylacetone}

Two independent experiments were performed where the bubbler was filled with trifluoroacetylacetone (tfa) instead of hfa to investigate the possibility to form volatile tfacomplexes. The nuclear reaction was ${ }^{50} \mathrm{Ti}+{ }^{124} \mathrm{Sn}$ (target \#5) to produce ${ }^{169} \mathrm{Hf}$. The He flow rate in these experiments was $1.5 \mathrm{~L} / \mathrm{min}, T_{\mathrm{R}}$ was $218{ }^{\circ} \mathrm{C}$, and the tfa was heated to $60^{\circ} \mathrm{C}$ and $70{ }^{\circ} \mathrm{C}$ in the two experiments, respectively. An ACC trap was placed at the exit of the quartz column (at "Pos. 2" in Fig. 2), and consequently, the off-line time pattern was used. Neither of the two experiments gave evidence for the transport of ${ }^{169} \mathrm{Hf}$. Either, no $\mathrm{Hf}(\mathrm{tfa})_{4}$ complexes were formed, or they are not volatile at temperatures of $30^{\circ} \mathrm{C}$, which was the temperature at the cold end of the quartz column. This is in agreement with [55].

\subsection{Measurement of the half-life of ${ }^{165} \mathrm{Hf}$}

There are several reports in the literature about the halflife of ${ }^{165} \mathrm{Hf}$ which are summarized in [65]. In most works a half-life of about $75 \mathrm{~s}$ has been measured: (76 $\pm 4 \mathrm{~s})$ [66], $(78.6 \pm 1.0 \mathrm{~s})$ [67], $(75 \pm 3 \mathrm{~s})$ [68], (1.28 $\pm 0.07 \mathrm{~min})$ [69], while others report a significantly longer half-life of about $100 \mathrm{~s}:(1.7 \pm 0.1 \mathrm{~min})[70,71]$. We have therefore measured the half-life of ${ }^{165} \mathrm{Hf}$ using the reaction ${ }^{120} \mathrm{Sn}\left({ }^{50} \mathrm{Ti}, 5 n\right){ }^{165} \mathrm{Hf}$ at a beam energy of $223.9 \mathrm{MeV}$ in the center of target \#4 $\left(300 \mu \mathrm{g} / \mathrm{cm}^{2}\right.$ thickness). The beam intensity was about $1.1 \times 10^{11} \mathrm{~s}^{-1}$. The nuclear reaction products were preseparated in the BGS and Hf was converted to the volatile $\mathrm{Hf}(\mathrm{hfa})_{4}$ complexes which were transported to an ACC trap installed outside of the irradiation cave. Five parallel irradiations were performed. Each lasted $12 \mathrm{~min}$ to reach equilibrium of ${ }^{165} \mathrm{Hf}$. The decay was followed for $7.5 \mathrm{~min}$. Fifteen individual $\gamma$-spectra were acquired, each lasting $30 \mathrm{~s}$. Due 


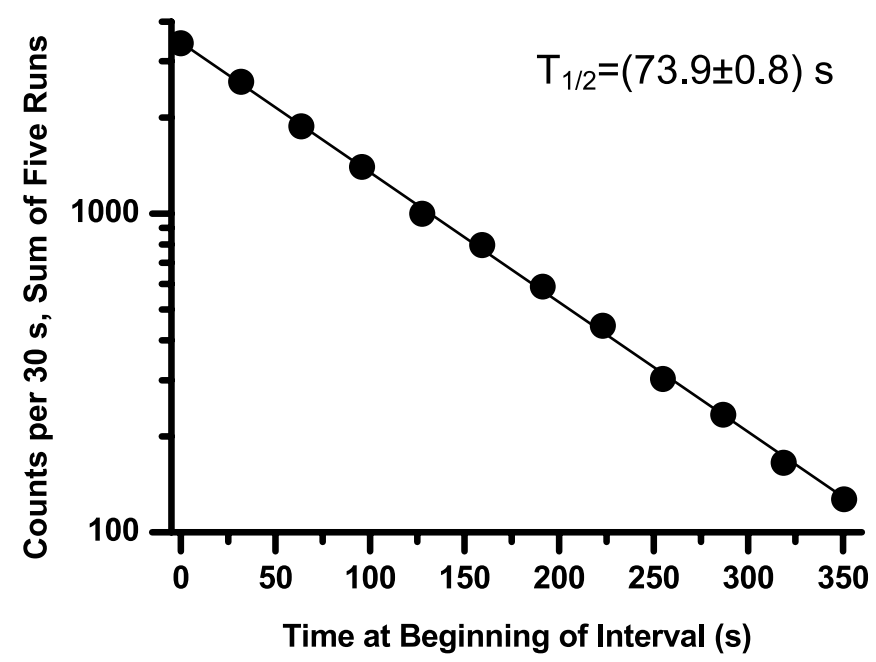

Fig. 10. Decay curve of ${ }^{165} \mathrm{Hf}$. Error bars are smaller than the size of the symbol.

to both, the physical preseparation and the chemically selective transport of volatile hfa-complexes, very clean $\gamma$-spectra were obtained. The peak areas were evaluated and after correction for dead time and minor time lapses between stopping of a file and starting of the next one, the decay curve was produced. All five files for each individual time bin were summed up, which resulted in a decay curve as shown in Fig. 10. An exponential fit to the data of the first twelve measurements resulted in a half-life of $(73.9 \pm 0.8) \mathrm{s}$, as indicated.

This half-life is a little bit shorter than but still in general agreement with the ones reported in [66-69], but clearly different from the ones from $[70,71]$.

\subsection{Thermochromatography}

Thermochromatography experiments with ${ }^{169} \mathrm{Hf}$ produced with targets \#5 and \#6 were conducted with FEP as well as with quartz TC columns. Prior to these experiments, the deposition temperature of hfa in the quartz columns was determined to be about $-65^{\circ} \mathrm{C}$ in both, the high-gas-flow as well as the low-gas-flow regime. Already in the first experiments, not unexpectedly, the presence of water on the surface proved to be an important point. In the initial runs, the deposit was observed to be a solid, likely the tetrol formed upon interaction of hfa with water [47]. Consequently, the quartz columns were pre-heated to $900{ }^{\circ} \mathrm{C}$ for about $30 \mathrm{~min}$, then connected to the gas flow system and flushed with dried He carrier gas before hfa was added. In these experiments, a white deposition zone was still observed at the same temperature, but upon heating to room temperature, it liquefied and released the strong typical hfa odor. The surface thus seemed to have been largely free from adsorbed water at temperatures above $-65^{\circ} \mathrm{C}$ and the $\mathrm{TC}$ experiments were performed using quartz columns pre-treated in the same way.

The presence of two different species, one formed at room temperature, the other mainly at elevated temperature could not be ruled out based on the studies of the transport efficiency as a function of $T_{\mathrm{R}}$. Therefore, TC experiments were conducted at $T_{\mathrm{R}}$ of $37{ }^{\circ} \mathrm{C}$ and $371{ }^{\circ} \mathrm{C}$ with the hope that different deposition patterns would corroborate the notion that indeed different chemical species were being transported. A preliminary account of some of these early experiments can be found in [72]. Since then, additional experiments have been performed, and, unfortunately, the encouraging results of these experiments could not be confirmed. In experiments conducted at low gas-flow rate $(900 \mathrm{~mL} / \mathrm{min})$, often two deposition peaks were observed, and at higher gas flow rates $(2100 \mathrm{~mL} / \mathrm{min})$, always only one. The deposition temperatures were around $0-20{ }^{\circ} \mathrm{C}$ and $<-20{ }^{\circ} \mathrm{C}$ in the $900 \mathrm{~mL} / \mathrm{min}$ experiments and around $0^{\circ}$ in the $2100 \mathrm{~mL} / \mathrm{min}$ experiments. The presence of minute amounts of moisture in the column could not be ruled out, especially as the BOLA connectors used to connect the quartz tubes to the transport capillary were likely not absolutely gas-tight. Free hfa has been shown to deposit at $-65^{\circ} \mathrm{C}$, but it cannot be ruled out that the complexes underwent chemisorption as soon as water traces were present on the column surface, leading to non-volatile species. Optical inspection of the quartz tubes after the TC experiments showed traces of a white solid at temperatures where ${ }^{169} \mathrm{Hf}$ was found. It was similar in appearance to the hfa deposit at $-65^{\circ} \mathrm{C}$ in the preparatory studies, where formation of the tetrol was assumed. In addition, a greenish deposition zone was found at the position of the higher-temperature peak in the $900 \mathrm{~mL} / \mathrm{min}$ experiments. It is assumed to originate from $\mathrm{Cu}(\mathrm{hfa})_{2}$, the hydrate of which is reported to be green [41], because, unfortunately, a short section of the tubing leading from the hfa enrichment station to "Pos. 1" consisted of $\mathrm{Cu}$ tubes. Around $(10 \pm 5) \%$ of the ${ }^{169} \mathrm{Hf}$ were found to have passed the quartz column and reached the ACC trap mounted behind it. Whether this activity was transported attached to aerosol particles or not is unclear. What can still be concluded from these studies is that there were no differences observed between experiments performed at $T_{\mathrm{R}}$ of $28^{\circ} \mathrm{C}$ and $371{ }^{\circ} \mathrm{C}$. To obtain better data, attempts were made to significantly reduce the moisture of the gas. Therefore, FEP tubes (i.d. $4 \mathrm{~mm}$ ), which were connected to the transport capillary with Swagelok fittings, were used as TC columns in the following experiments. Thermochromatograms obtained in these studies are displayed in Fig. 11.

Using a Monte Carlo procedure [73] simulating the migration of a volatile species along the column with the adsorption enthalpy $-\Delta H_{\mathrm{a}}$ on the column surface as the only free parameter yielded the dashed curves in Fig. 11 when $-\Delta H_{\mathrm{a}}=62 \mathrm{~kJ} / \mathrm{mol}$ was used. The deposition pattern looked very similar to the one in the quartz columns. We conclude that the TC experiments gave no indication that different species were formed at different $T_{\mathrm{R}}$, and that the deposition process is not clear. It was not possible to find experiment conditions where deposition of the species above $0{ }^{\circ} \mathrm{C}$ was observed.

\subsection{Isothermal gas chromatography}

A different approach to investigate the interaction of the compound with PFA was chosen in the following experiments, mainly to overcome problems associated with surfaces kept below $0^{\circ}$. The 4-m long central section of the

PFA-capillary connecting the RTC with the ACC trap was used as an isothermal chromatography column with the goal 

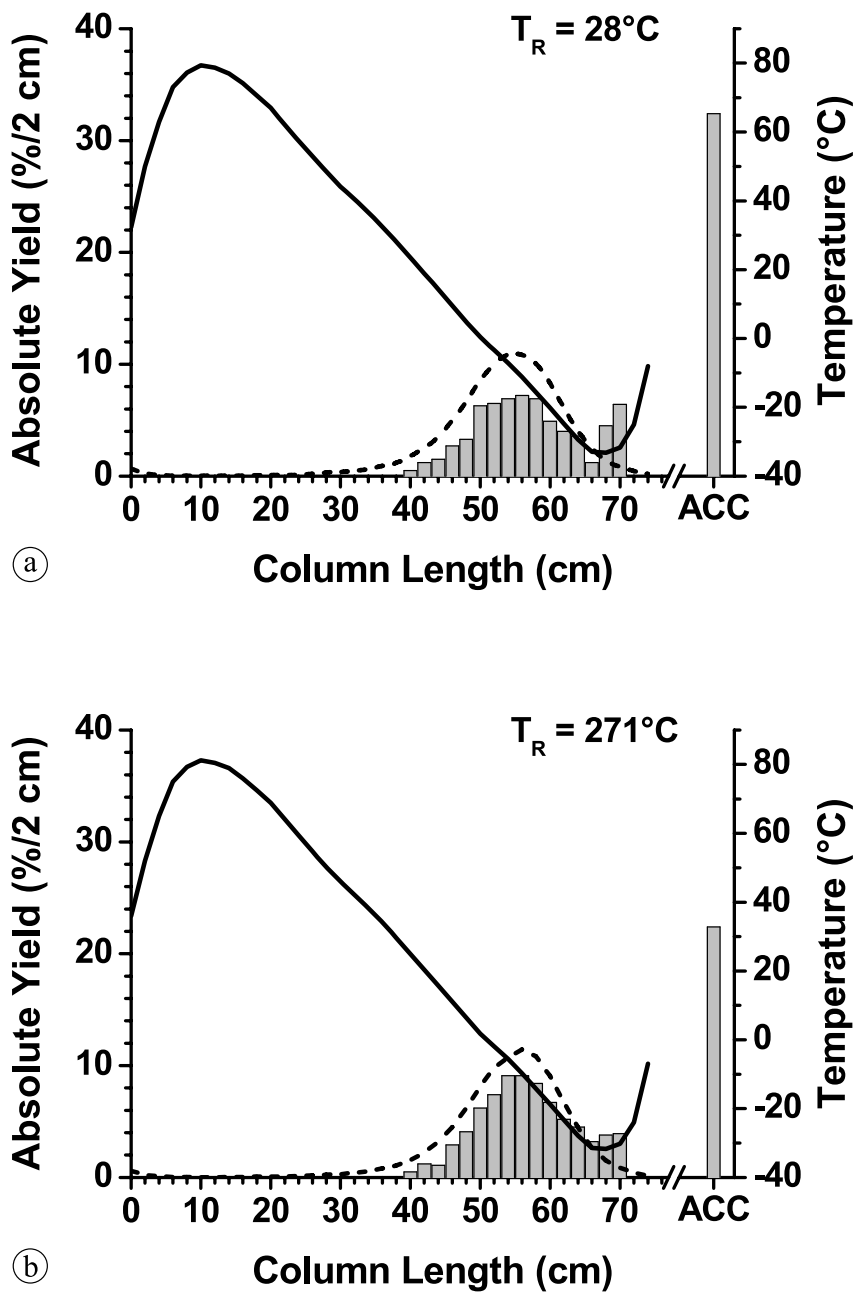

Fig. 11. Thermochromatograms of ${ }^{169} \mathrm{Hf}$ deposited in quartz columns in runs with reaction temperatures of $28^{\circ} \mathrm{C}(\mathbf{a})$ and $271^{\circ} \mathrm{C}(\mathbf{b})$. The distribution of ${ }^{169} \mathrm{Hf}$ is given by the bars (left-hand scale), the temperature gradient is indicated by the solid line (right-hand scale). The dashed lines indicate results of a Monte Carlo simulation [73] for the expected deposition pattern of a species with 3.24 min half-life and adsorption enthalpy on FEP of $-62 \mathrm{~kJ} / \mathrm{mol}$.

of obtaining the adsorption enthalpy of the Hf complexes on PFA Teflon. These experiments were performed with ${ }^{162} \mathrm{Hf}$ (produced with target \#3, thickness: $384 \mu \mathrm{g} / \mathrm{cm}^{2}$ ) in the highflow-rate regime. The quartz wool plug at the RTC exit was heated to $T_{\mathrm{R}}=357^{\circ} \mathrm{C}$. Transported species were collected in an ACC trap placed in front of the $\gamma$-detector and the spectra were acquired in the on-line time pattern. Experiments at eight different isothermal temperatures were performed and the yield normalized to the maximum measured value. Care was taken to keep the column temperature above $0{ }^{\circ} \mathrm{C}$ to avoid coverage of the surface with an ice layer and accordingly, the lowest used temperature was $+2{ }^{\circ} \mathrm{C}$. The resulting isothermal chromatogram is displayed in Fig. 12, together with the results of Monte Carlo simulations of the migration of the complexes through the capillary [73] assuming adsorption enthalpies of $-\Delta H_{\mathrm{ads}}=(57 \pm 3) \mathrm{kJ} / \mathrm{mol}$.

The fact that only $(6 \pm 1) \%$ of the maximum yield was observed at $2{ }^{\circ} \mathrm{C}$ indicates that no appreciable amount of ${ }^{162} \mathrm{Hf}$ was transported by aerosol transport but that instead, mobile adsorption was taking place inside the PFA tube. It is noteworthy that a species with an adsorption enthalpy

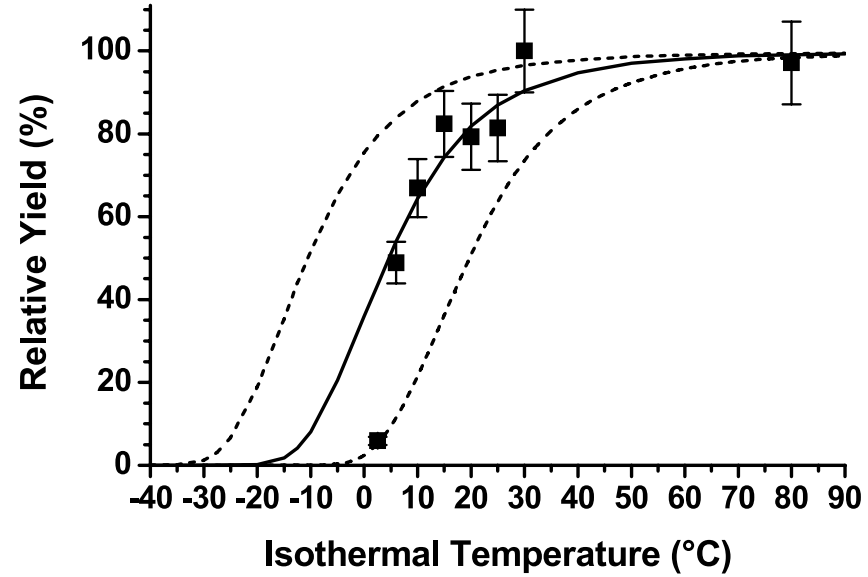

Fig. 12. Isothermal chromatogram of ${ }^{162} \mathrm{Hf}(\mathrm{hfa})_{4}$. A 4-m long isothermal section of a PFA Teflon tube served as isothermal chromatography column. The gas flow rate was $2100 \mathrm{~mL} / \mathrm{min}$. The solid line represents the result of a Monte Carlo simulation of the transport process with an adsorption enthalpy of $-57 \mathrm{~kJ} / \mathrm{mol}$, the dashed lines indicate the $1 \sigma$ limits of $\pm 3 \mathrm{~kJ} / \mathrm{mol}$.

of $-57 \mathrm{~kJ} / \mathrm{mol}$ would have been transported to lower temperatures in the TC studies described in Sect. 3.3, provided no irreversible adsorption on the column takes place. This supports the assumption that the chromatography column surfaces were not clean in the TC experiments described in Sect. 3.3.

\section{Discussion}

\subsection{Comparison with experiments without physical preseparation}

Fedoseev et al. [55] have reported TC studies of Hf using long-lived $\left(T_{1 / 2}=12-16 \mathrm{~h}\right){ }^{170,171} \mathrm{Hf}$ and have found depositions at $\sim 40{ }^{\circ} \mathrm{C}$ in their TC column, which was made from glass. Their reaction temperature was likely the start temperature of their temperature gradient, i.e., $\sim 180-200{ }^{\circ} \mathrm{C}$. Overall, these results are not in contradiction to ours, as deposition of different surface materials (quartz vs. glass) and especially different amounts of impurities in the gas can be expected to shift the deposition temperatures by a few tens of degrees. As stated in the Introduction, their method (adding hfa only at the exit of the recoil chamber due to the absence of a physical preseparator) resulted in lower yields, $\sim 50 \%$ even for the very long-lived Hf isotopes used, compared to $\sim 70-80 \%$ in our case even for much shorter-lived isotopes.

\subsection{Transport time}

From the absolute yield data shown in Figs. 8 and 9, the total time that passed between the entry of the EVRs into the RTC and their arrival in the ACC traps can be calculated if it is assumed that yields below $100 \%$ are due to radioactive decay during that time. From the figures in Sect. 3.1 can be seen that yields over $90 \%$ were never reached, not even by longlived isotopes. This may be due to, e.g., imperfect flushing of the RTC or losses through irreversible adsorption on the walls of the RTC or quartz wool plug. These losses are unrelated to decay losses, and consequently, for the analysis 


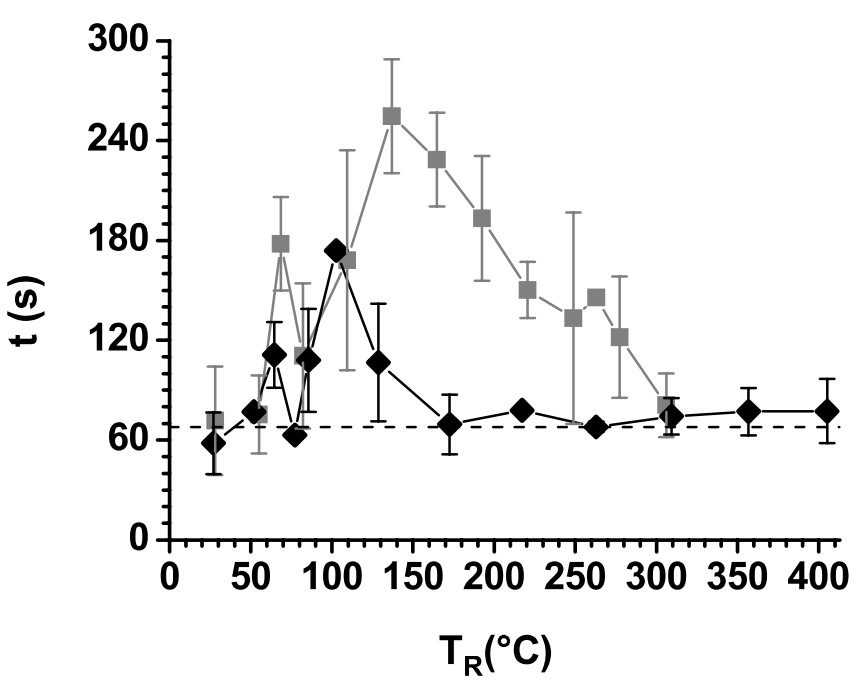

Fig. 13. Average time for $\mathrm{Hf}$ atoms between their entry into the RTC and their arrival in a trap, based on the yield data from Figs. 5, 6, 8, and 9. Transport times from the low-flow-rate regime are shown by gray squares, data from the high-flow-rate regime with black diamonds. Error bars represent one standard deviation for data points based on results of $>1$ isotope. Two minima are visible, one at temperatures of $<75^{\circ} \mathrm{C}$ and another one at higher temperatures (for the high-flow-rate regime $\sim>150{ }^{\circ} \mathrm{C}$ ). The dashed horizontal line indicates the half-life of ${ }^{261 a} \mathrm{Rf}$ of $68 \mathrm{~s}$ [28].

here, $10 \%$ of the total observed loss (total loss $=100 \%-$ observed yield) was ascribed to irreversible processes with the remainder being caused by decay loss during transport. The absolute yields (from Fig. 3, 4, 8, and 9) were thus divided by 0.9 to calculate the transport time. All samples were taken in just two different time patterns (on-line and off-line), and the standard equations for growth and decay of a radioactive species were employed to calculate how many half-lives had passed between entry in the RTC and arrival in the traps. This was done for i) ${ }^{169} \mathrm{Hf}$ (off-line), ii) ${ }^{169} \mathrm{Hf}$ (on-line), iii) ${ }^{165} \mathrm{Hf}$ (on-line), and ${ }^{162} \mathrm{Hf}$ (on-line). Data point with absolute yields $<1 \%$ were disregarded in the analysis. Fig. 13 shows the result of the analysis. Every data point shown is the average of one to four values, the error bars represent the standard deviation in case more than one of the data series i)-iv) described above were available. The lowflow-rate regime series includes data points where more than only ${ }^{169} \mathrm{Hf}$ off-line data (series i) were available.

In agreement with the yield data (Section 3.1), fast transport occurs in both gas-flow regimes at low temperatures $\left(<75^{\circ} \mathrm{C}\right)$. With increasing $T_{\mathrm{R}}$, a maximum is reached, which is significantly longer for the low-flow-rate regime. Increasing the temperature further decreases the transport time. Transport in the low-flow-rate regime is generally slower, but still reaches values as short as those of the high-flowrate regime at $T_{\mathrm{R}} \sim 300{ }^{\circ} \mathrm{C}$. In the high-flow-rate regime, the transport time becomes shorter at much lower temperatures of $\sim 150{ }^{\circ} \mathrm{C}$ already and stays constant at $\sim 70$ s. It appears reasonable to assume that two processes contribute to the total transport time: i) the time taken by the chemical reaction to form the volatile complex, and ii) the time that the transport of the species from the RTC to the trap takes. Process i) can be expected to be strongly temperature dependent while process ii) should be independent of the temperature as this is varied over only a very short section of the total passed volume. In a rough approximation, the time it takes to exchange the gas of the total volume of the RTC $\left(322 \mathrm{~cm}^{3}\right)$ plus the transport capillary $\left(10 \mathrm{~cm}^{3}\right)$ once can be calculated for the two flow rates of $1300 \mathrm{~mL} / \mathrm{min}$ and $2100 \mathrm{~mL} / \mathrm{min}$. It follows that in the two regimes, about $15 \mathrm{~s}$ (low-flow-rate regime) and $9 \mathrm{~s}$ (high-flow-rate regime) are needed to exchange the gas once. If the remainder of the observed total transport time is ascribed to the chemical reaction time, it follows that the chemical reaction requires roughly $1 \mathrm{~min}$ in the optimum case, i.e., at $<70^{\circ} \mathrm{C}$ and at high temperatures. The quality of the transport time data is clearly limited and not high enough to draw conclusions about the kinetics of the reaction under different experimental conditions. It is good enough, though, to conclude that the total time it takes to convert Hf into the volatile complexes and transport them to a counting station outside the irradiation cave, is comparable to the half-life of ${ }^{261 a} \mathrm{Rf}$, and therefore short enough that a future experiment with this isotope appears feasible. This is corroborated by the fact that $14-\mathrm{s}{ }^{87 \mathrm{~m}} \mathrm{Zr}$ was observed in some of the $\mathrm{Zr}$ experiments (with the ${ }^{\text {nat }} \mathrm{Ge}$ target, where ${ }^{87 \mathrm{~m}, \mathrm{~g}} \mathrm{Nb}$, which have an interfering $\gamma$-line at $201.0 \mathrm{keV}$, are not produced). The absolute yields of ${ }^{87 \mathrm{~m}} \mathrm{Zr}$ could not be determined as the measurement of a 14-s isotope in a catcher foil was not possible due to the time delay between the end of bombardment and the start of counting of the retrieved catcher foil, however, the general trend of yield $v s . T_{\mathrm{R}}$ was the same as observed for short-lived Hf isotopes. As ${ }^{87 \mathrm{~m}} \mathrm{Zr}$ decays exlusively by $\gamma$-ray emission, it was also not possible to measure it with the BGS focal plane detector.

One question that remains open is whether two different species are produced at low and high $T_{\mathrm{R}}$. To our knowledge, only one volatile hfa-complex of Hf is known, namely $\mathrm{Hf}(\mathrm{hfa})_{4}$. Adduct formation is a well known process for many $\beta$-diketonates, however, under our experimental conditions, only hydrate adducts seem possible, none of which are known for $\mathrm{Hf}$ (in contrast to, e.g., $\mathrm{Cu}$, where the formation of a monohydrate is known [41]). The presence of a rather unstable volatile adduct that decomposes around $75^{\circ} \mathrm{C}$ would explain our observed results. In the temperature range above $\sim 150{ }^{\circ} \mathrm{C}$, formation of the $\mathrm{M}(\mathrm{hfa})_{4}(\mathrm{M}=\mathrm{Zr}$, Hf) takes place. At temperatures above $\sim 400{ }^{\circ} \mathrm{C}$, decomposition of hfa [62-64] (and possibly also of the complexes [48]) sets in, resulting in non-chemically selective aerosol transport. The $3 \mathrm{~d}$ members of neighboring groups 5 and 6, i.e., $\mathrm{Nb}$ and $\mathrm{Mo}$, have been shown to be transported as hfa complexes to a significantly smaller extent, if at all. This chemical system therefore seems to allow the chemical separation of group 4 elements from group 5/6 elements. Attempts to transport $\mathrm{Hf}$ in the form of volatile tfa-complexes have failed. It is not clear if that is due to too slow chemical reaction, thermal instability of the complexes, or too low volatility for transport at $\sim 50{ }^{\circ} \mathrm{C}$.

\section{Conclusion and outlook}

In this work, volatile metal complexes $\mathrm{M}(\mathrm{hfa})_{4}(\mathrm{M}=\mathrm{Zr}$, Hf) have been produced using physically preseparated shortlived radioisotopes of the metals. Using a ${ }^{18} \mathrm{O}^{4+} /{ }^{50} \mathrm{Ti}^{11+}$ cocktail beam allowed near-simultaneous production of appropriate isotopes of both elements. It was shown that phys- 
ical preseparation allows the formation of thermally fragile complexes, i.e., such with organic ligands, of heavy-ion reaction products with half-lives of the order of one minute. The technique can thus be expected to be applicable to transactinides (provided samples suitable for $\alpha$-spectroscopy can be prepared). In the chemical system studied here, the homolog TAN element would be Rf. The time required to transform the metal into the volatile complex and transport it to an appropriate counting system is short enough for experiments with, e.g., $68-\mathrm{s}{ }^{261 \mathrm{a}} \mathrm{Rf}$. This isotope, produced in the ${ }^{244} \mathrm{Pu}\left({ }^{22} \mathrm{Ne}, 5 n\right)$ reaction, was recently studied in preseparation experiments at the new gas-filled recoil separator TASCA at GSI [74] and its decay measured in an external wheel-type detection system. Systematic studies of the stopping power of slow EVRs in Mylar (which is typically used as the RTC window) have been performed as well [75], which are helpful for the choice of the thickness of the RTC window and the depth of the RTC. In the preparation of hfa-experiments with $\mathrm{Rf}$, a few improvements should be implemented. It was, e.g., observed that the transport yield depended on the time between the last filling of the bubbler with hfa and the start of the experiment (which was circumvented by always filling the bubbler to the same level before the start of an experiment). This is likely due to the different fill level of the bubbler. For future studies, a system, where this level stays constant without user interaction for extended periods of time would be advantageous. Another development of paramount importance is the preparation of samples suitable for $\alpha$-spectroscopy. Experiments where the transport time is measured using a pulsed beam could be performed to corroborate the total transfer times from the RTC to the detection station found here with $\gamma$-decaying isotopes. The big advantage when using $\alpha$-decaying isotopes is that such measurements are largely background-free, i.e., their signal/noise ratio is much larger compared to $\gamma$-spectroscopy measurements. In our experiments, this prevented the direct measurement of the transport time with a pulsed beam and led us to use isotopes with different half-lives.

The broader impact of the results reported here is that new compound classes, such as organometallic compounds, of transactinides appear to be accessible with physical preseparation.

Acknowledgment. We thank Yong Hee Chung, Hassan Mahmud, Sarah Gallaher, and Peter Zielinski for their help with the experiments and Wayne Lukens for interesting discussions. The mechanical shop at the 88-Inch Cyclotron built much of the experimental equipment which we gratefully acknowledge. We also thank the staff of the LBNL 88Inch Cyclotron for providing the stable "cocktail" beams. R. Dressler made us aware of the controversial situation concerning the reported half-lives of ${ }^{165} \mathrm{Hf}$. These studies were supported in part by the Swiss National Science Foundation and the Director, Office of Science, Office of High Energy and Nuclear Physics, Division of Nuclear Physics, and the Office of Basic Energy Sciences, Chemical Sciences Division, U.S. Department of Energy under Contract Nos. DE-AC03-76SF00098 and DE-AC02-05CH11231.

\section{References}

1. Schädel, M.: Chemistry of the superheavy elements. Angew. Chem. Int. Ed. 45, 368-401 (2006).

2. Schädel, M.: The chemistry of superheavy elements. Kluwer Academic Publishers, Dordrecht, The Netherlands (2003).
3. Eichler, R., Aksenov, N. V., Belozerov, A. V., Bozhikov, G. A., Chepigin, V. I., Dmitriev, S. N., Dressler, R., Gäggler, H. W., Gorshkov, V. A., Haenssler, F., Itkis, M. G., Laube, A., Lebedev, V. Y., Malyshev, O. N., Oganessian, Y. T., Petrushkin, O. V., Piguet, D., Rasmussen, P., Shishkin, S. V., Shutov, A. V., Svirikhin, A. I., Tereshatov, E. E., Vostokin, G. K., Wegrzecki, M., Yeremin, A.: Chemical characterization of element 112. Nature 447, 72-75 (2007).

4. Nai-Qi, Y., Jost, D. T., Baltensperger, U., Gäggeler, H. W.: The Saphir gas-jet and a first application to an on-line separation of niobium. Radiochim. Acta 47, 1-7 (1989).

5. Wollnik, H., Wilhelm, H. G., Röbig, G., Jungclas, H.: The improvement of a gas-jet system by the use of an aerosol generator. Nucl. Instrum. Methods 127, 539-545 (1975).

6. Wollnik, H.: Principles behind a He-jet system and its application for isotope separation. Nucl. Instrum. Methods 139, 311-318 (1976).

7. Gäggeler, H. W., Jost, D. T., Baltensperger, U., Weber, A., Kovacs, A., Vermeulen, D., Türler, A.: OLGA II, an on-line gas chemistry apparatus for applications in heavy element research. Nucl. Instrum. Methods A 309, 201-208 (1991).

8. Eichler, R., Brüchle, W., Dressler, R., Düllmann, Ch. E., Eichler, B., Gäggeler, H. W., Gregorich, K. E., Hoffman, D. C., Hubener, S., Jost, D. T., Kirbach, U. W., Laue, C. A., Lavanchy, V. M., Nitsche, H., Patin, J. B., Piguet, D., Schädel, M., Shaughnessy, D. A., Strellis, D. A., Taut, S., Tobler, L., Tsyganov, Y. S., Türler, A., Vahle, A., Wilk, P. A., Yakushev, A. B.: Chemical characterization of bohrium (element 107). Nature 407, 63-65 (2000).

9. Zvara, I., Yakushev, A. B., Timokhin, S. N., Honggui, X., Perelygin, V. P., Chuburkov, Y. T.: Chemical identification of element 106 (thermochromatography of oxochlorides). Radiochim. Acta 81, 179-187 (1998).

10. Düllmann, Ch. E., Brüchle, W., Dressler, R., Eberhardt, K., Eichler, B., Eichler, R., Gäggeler, H. W., Ginter, T. N., Glaus, F., Gregorich, K. E., Hoffman, D. C., Jäger, E., Jost, D. T., Kirbach, U. W., Lee, D. M., Nitsche, H., Patin, J. B., Pershina, V., Piguet, D., Qin, Z., Schädel, M., Schausten, B., Schimpf, E., Schött, H. J., Soverna, S., Sudowe, R., Thörle, P., Timokhin, S. N., Trautmann, N., Türler, A., Vahle, A., Wirth, G., Yakushev, A. B., Zielinski, P. M.: Chemical investigation of hassium (element 108). Nature 418, 859-862 (2002).

11. Omtvedt, J. P., Alstad, J., Breivik, H., Dyve, J. E., Eberhardt, K., Folden III, C. M., Ginter, T., Gregorich, K., Hult, E. A., Johansson, M., Kirbach, U. W., Lee, D. M., Mendel, M., Nähler, A., Ninov, V., Omtvedt, L. A., Patin, J. B., Skarnemark, G., Stavsetra, L., Sudowe, R., Wiehl, N., Wierczinski, B., Wilk, P. A., Zielinski, P. M., Kratz, J. V., Trautmann, N., Nitsche, H., Hoffman, D. C.: SISAK liquid-liquid extraction experiments with prespearated ${ }^{257}$ Rf. J. Nucl. Radiochem. Sci. 3, 121-124 (2002).

12. Düllmann, Ch. E., Folden III, C. M., Gregorich, K. E., Hoffman, D. C., Leitner, D., Pang, G. K., Sudowe, R., Zielinski, P. M., Nitsche, H.: Heavy-ion-induced production and physical preseparation of short-lived isotopes for chemistry experiments. Nucl. Instrum. Methods A 551, 528-539 (2005).

13. Düllmann, Ch. E.: Physical preseparation for chemistry experiments. Czech. J. Phys. 56(Suppl. D), D333-D338 (2006).

14. Düllmann, Ch. E.: Physical preseparation: a powerful new method for transactinide chemists. Eur. Phys. J. D 45, 75-80 (2007).

15. Kirbach, U. W., Folden III, C. M., Ginter, T. N., Gregorich, K. E., Lee, D. M., Ninov, V., Omtvedt, J. P., Patin, J. B., Seward, N. K., Strellis, D. A.: The cryo-thermochromatographic separator (CTS): a new rapid separation and $\alpha$-detection system for on-line chemical studies of highly volatile osmium and hassium $(Z=108)$ tetroxides. Nucl. Instrum. Methods A 484, 587-594 (2002).

16. Stavsetra, L., Gregorich, K. E., Alstad, J., Breivik, H., Eberhardt, K., Folden III, C. M., Ginter, T. N., Johansson, M., Kirbach, U. W., Lee, D. M.: Liquid-scintillation detection of preseparated ${ }^{257} \mathrm{Rf}$ with the SISAK-system. Nucl. Instrum. Methods A 543, 509-516 (2005).

17. Omtvedt, J. P., Alstad, J., Bjørnstad, T., Düllmann, Ch. E., Gregorich, K. E., Hoffman, D. C., Nitsche, H., Opel, K., Polakova, D., Samadani, F., Schulz, F., Skarnemark, G., Stavsetra, L., Sudo- 
we, R., Zheng, L.: Chemical properties of the transactinide elements studied in liquid phase with SISAK. Eur. Phys. J. D 45, 91-97 (2007).

18. Sudowe, R., Calvert, M., Düllmann, Ch. E., Farina, L. M., Folden III, C. M., Gregorich, K. E., Gallaher, S. E. H., Hoffman, D. C., Nelson, S. L., Phillips, D. C., Schwantes, J. M., Wilson, R. E., Zielinski, P. M., Nitsche, H.: Extraction of short-lived zirconium and hafnium isotopes using crown ethers: A model system for the study of rutherfordium. Radiochim. Acta 94, 123-129 (2006).

19. Ninov, V., Gregorich, K. E., McGrath, C. A.: The Berkeley GasFilled Separator. In: Proc. Conf. on Exotic Nuclei and Atomic Masses, ENAM 98. (Sherrill, B. M., Morrissey, D. J., Davids, C. N., eds.) Woodbury, New York, AIP Conf. Proc. 455, 704 (1998).

20. Morita, K., Yoshida, A., Inamura, T. T., Koizumi, M., Nomura, T., Fujioka, M., Shinozuka, T., Miyatake, H., Sueki, K., Kudo, H., Nagai, Y., Toriyama, T., Yoshimura, K., Hatsukawa, Y.: RIKEN isotope separator on-line GARIS/IGISOL. Nucl. Instrum. Methods B 70, 220-225 (1992).

21. Haba, H., Kaji, D., Kikunaga, H., Akiyama, T., Sato, N., Morimoto, K., Yoneda, A., Morita, K., Takabe, T., Shinohara, A.: Development of gas-jet transport system coupled to the RIKEN gas-filled recoil ion separator GARIS for superheavy element chemistry. J. Nucl. Radiochem. Sci. 8, 55-58 (2007).

22. Subotic, K., Oganessian, Y. T., Utyonkov, V. K., Lobanov, Y. V., Abdullin, F. S., Polyakov, A. N., Tsyganov, Y. S., Ivanov, O. V.: Evaporation residue collection efficiencies and position spectra of the Dubna gas-filled recoil separator. Nucl. Instrum. Methods A 481, 71-80 (2002).

23. Düllmann, Ch. E.: Physical separators for the heaviest elements. Nucl. Instrum. Methods B 266, 4123-4130 (2008).

24. Hofmann, S., Heßberger, F. P., Ackermann, D., Antalic, S., Cagarda, P., Kindler, B., Kuusiniemi, P., Leino, M., Lommel, B., Malyshev, O. N.: Properties of heavy nuclei measured at the GSI SHIP. Nucl. Phys. A 734, 93-100 (2004).

25. Dragojević, I., Gregorich, K. E., Düllmann, Ch. E., Garcia, M. A., Gates, J. M., Nelson, S. L., Stavsetra, L., Sudowe, R., Nitsche, H.: Influence of projectile neutron number in the ${ }^{208} \mathrm{~Pb}\left({ }^{48} \mathrm{Ti}, n\right)^{255} \mathrm{Rf}$ and ${ }^{208} \mathrm{~Pb}\left({ }^{50} \mathrm{Ti}, n\right){ }^{257} \mathrm{Rf}$ reactions. Phys. Rev. C 78, 024605 (2008).

26. Kadkhodayan, B., Türler, A., Gregorich, K. E., Baisden, P. A., Czerwinski, K. R., Eichler, B., Gäggeler, H. W., Hamilton, T. M., Jost, D. T., Kacher, C. D., Kovacs, A., Kreek, S. A., Lane, M. R., Mohar, M. F., Neu, M. P., Stoyer, N. J., Sylwester, E. R., Lee, D. M., Nurmia, M. J., Seaborg, G. T., Hoffman, D. C.: On-line gas chromatographic studies of chlorides of rutherfordium and homologs Zr and Hf. Radiochim. Acta 72, 169-178 (1996).

27. Ghiorso, A., Nurmia, M., Eskola, K., Eskola, P.: ${ }^{261}$ Rf; new isotope of element 104. Phys. Lett. 32B, 95-98 (1970).

28. Asai, M.: Alpha-gamma spectroscopy of $N=155$ and $157 \mathrm{nu}-$ clei using a gas-jet transport technique. Oral presentation at the $3^{\text {rd }}$ International Conference on the Chemistry and Physics of the Transactinide Elements, TAN 07, Davos, Switzerland, September 23-28 (2007).

29. Dvorak, J., Brüchle, W., Chelnokov, M., Dressler, R., Düllmann, Ch. E., Eberhardt, K., Gorshkov, V., Jäger, E., Krücken, R., Kuznetsov, A., Nagame, Y., Nebel, F., Novackova, Z., Qin, Z., Schädel, M., Schausten, B., Schimpf, E., Semchenkov, A., Thörle, P., Türler, A., Wegrzecki, M., Wierczinski, B., Yakushev, A., Yeremin, A.: Doubly magic nucleus ${ }^{270} \mathrm{Hs}_{162}$. Phys. Rev. Lett. 97, 242501 (2006).

30. Dvorak, J., Brüchle, W., Chelnokov, M., Dressler, R., Düllmann, Ch. E., Dvorakova, Z., Eberhardt, K., Jäger, E., Krücken, R., Kuznetsov, A., Nagame, Y., Nebel, F., Nishio, K., Perego, R., Qin, Z., Schädel, M., Schausten, B., Schimpf, E., Schuber, R., Semchenkov, A., Thörle, P., Türler, A., Wegrzecki, M., Wierczinski, B., Yakushev, A., Yeremin, A.: Observation of the $3 n$ evaporation channel in the complete hot-fusion reaction ${ }^{26} \mathrm{Mg}+{ }^{248} \mathrm{Cm}$ leading to the new superheavy nuclide ${ }^{271} \mathrm{Hs}$. Phys. Rev. Lett. 100, 132503 (2008).

31. Lazarev, Y. A., Lobanov, Y. V., Oganessian, Y. T., Utyonkov, V. K., Abdullin, F. S., Polyakov, A. N., Rigol, J., Shirokovsky, I. V., Tsyganov, Y. S., Iliev, S., Subbotin, V. G., Sukhov, A. M., Buklanov, G. V., Mezentsev, A. N., Subotic, K., Moody, K. J., Stoyer,
N. J., Wild, J. F., Lougheed, R. W.: Decay properties of ${ }^{257}$ No, ${ }^{261}$ Rf, and ${ }^{262}$ Rf. Phys. Rev. C 62, 064307 (2000).

32. Nagame, Y., Asai, M., Haba, H., Goto, S., Tsukada, K., Nishinaka, I., Nishio, K., Ichikawa, S., Toyoshima, A., Akiyama, K., Nakahara, H., Sakama, M., Schädel, M., Kratz, J. V., Gäggeler, H. W., Türler, A.: Production cross sections of ${ }^{261} \mathrm{Rf}$ and ${ }^{262} \mathrm{Db}$ in bombardments of ${ }^{248} \mathrm{Cm}$ with ${ }^{18} \mathrm{O}$ and ${ }^{19} \mathrm{~F}$ ions. J. Nucl. Radiochem. Sci. 3, 85-88 (2002).

33. Gates, J. M., Garcia, M. A., Gregorich, K. E., Düllmann, Ch. E., Dragojević, I., Dvorak, J., Eichler, R., Folden III, C. M., Loveland, W., Nelson, S. L., Pang, G. K., Stavsetra, L., Sudowe, R., Türler, A., Nitsche, H.: Synthesis of rutherfordium isotopes in the ${ }^{238} \mathrm{U}\left({ }^{26} \mathrm{Mg}, x n\right){ }^{264-x} \mathrm{Rf}$ reaction and study of their decay properties. Phys. Rev. C 77, 034603 (2008).

34. Zvara, I., Chuburkov, Y. T., Belov, V. Z., Buklanov, G. V., Zakhvataev, B. B., Zvarova, T. S., Maslov, O. D., Caletka, R., Shalaevsky, M. R.: Experiments on chemistry of element 104-kurchatovium - V: Adsorption of kurchatovium chloride from the gas stream on surfaces of glass and potassium chloride. J. Inorg. Nucl. Chem. 32, 1885 (1970).

35. Zvára, I., Belov, V. Z., Chelnokov, L. P., Domanov, V. P., Hussonois, M., Korotkin, Y. S., Schegolev, V. A., Shalayevsky, M. R.: Chemical separation of kurchatovium. Inorg. Nucl. Chem. Lett. 7, 1109-1116 (1971).

36. Türler, A., Gäggeler,H. W., Gregorich, K. E., Barth, H., Brüchle, W., Czerwinski, K. R., Gober, M. K., Hannink, N. J., Henderson, R. A., Hoffman, D. C., Jost, D. T., Kacher, C. D., Kadkhodayan, B., Kovacs, J., Kratz, J. V., Kreek, S. A., Lee, D. M., Leyba, J. D., Nurmia, M. J., Schädel, M., Scherer, U., Schimpf, E., Vermeulen, D., Weber, A., Zimmerman, H. P., Zvara, I.: Gas phase chromatography of halides of elements 104 and 105. J. Radioanal. Nucl. Chem. 160, 327-339 (1992).

37. Sylwester, E. R., Gregorich, K. E., Lee, D. M., Kadkhodayan, B., Türler, A., Adams, J. L., Kacher, C. D., Lane, M. R., Laue, C. A., McGrath, C. A., Shaughnessy, D. A., Strellis, D. A., Wilk, P. A., Hoffman, D. C.: On-line gas chromatographic studies of Rf, Zr, and Hf bromides. Radiochim. Acta 88, 837-843 (2000).

38. Sievers, R. E., Sadlowski, J. E.: Volatile metal complexes. Science 201, 217-223 (1978).

39. Uden, P. C., Henderson, D. E.: Determination of metals by gas chromatography of metal complexes. The Analyst 102, 889-916 (1977).

40. Berg, E. W., Truemper, J. T.: A study of the volatile characteristics of various metal $\beta$-diketone chelates. J. Phys. Chem. 64, 487-490 (1960).

41. Fahlman, B. D., Barron, A. R.: Substituent effects on the volatility of metal $\beta$-diketonates. Adv. Mater. Opt. Electron. 10, 223-232 (2000).

42. Hubert-Pfalzgraf,L. G.: Metal alkoxides and $\beta$-diketonates as precursors for oxide and non-oxide thin films. Appl. Organomet. Chem. 6, 627-643 (1992).

43. Jones, A. J., Chalker, P. R.: Some recent developments in the chemical vapour deposition of electroceramic oxides. J. Phys. D Appl. Phys. 36, R80-R95 (2003).

44. Pashkevich, K. I., Saloutin, V. I., Postovskii, I. Y.: Fluorine-containing $\beta$-diketones. Russ. Chem. Rev. 50, 180-195 (1981). Translated from Uspekhi Khimii 50, 325-354 (1981).

45. Burdett, J. L., Rogers, M. T.: Keto-enol tautomerism in $\beta$-dicarbonyls studied by nuclear magnetic resonance spectroscopy. I. Proton chemical shifts and equilibrium constants of pure compounds. J. Am. Chem. Soc. 86, 2105-2109 (1964).

46. Bouwman, E., Huffman, J. C., Lobkovsky, E. B., Christou, G., Tsai, H.-L., Hendrickson, D. N.: A new fluorinated tetraalkoxide ligand derived from the hydration of hexafluoroacetylacetone. Inorg. Chem. 31, 4436-4438 (1992).

47. Schultz, B. G., Larsen, E. M.: Evidence for a solid dihydrate of hexafluoroacetylacetone. J. Am. Chem. Soc. 71, 3250-3251 (1949).

48. Chattoraj, S. C., Lynch, C. T., Mazdiyasni, K. S.: Hexafluoroacetylacetonates of zirconium and hafnium. Inorg. Chem. 7, 2501-2505 (1968).

49. Morozova, N. B., Sysoev, S. V., Igumenov, I. K., Golubenko, A. N.: Study of temperature dependence of saturated vapour pressure of zircomium(IV) $\beta$-diketonates. J. Therm. Anal. 46, 1367-1373 (1996). 
50. Sievers, R. E., Ponder, B. W., Morris, M. L., Moshier, R. W.: Gas phase chromatography of metal chelates of acetylacetone, trifluoroacetylacetone, and hexafluoroacetylacetone. Inorg. Chem. 2, 693-698 (1963).

51. Travnikov, S. S., Fedoseev, E. V., Davydov, A. V., Myasoedov, B. F.: Separation of elements by means of fractional sublimation of their $\beta$-diketonates in the vapours of $\beta$-diketones. J. Radioanal. Nucl. Chem. Lett. 93, 217-226 (1985).

52. Ono, S., Kaneko, T., Goto, S., Kudo, H.: Thermochromatographic behavior of fission products combined with dipivaloylmethane. J. Radioanal. Nucl. Chem. 255, 571-574 (2003).

53. Fedoseev, E. V., Aizenberg, M. I., Timokhin, S. N., Travnikov, S. S., Zvara, I., Davydov, A. V., Myasedov, B. F.: Synthesis and thermochromatographic investigation of volatile hexafluoroacetylacetonate complexes of mendelevium and fermium. J. Radioanal. Nucl. Chem. 142, 459-465 (1990).

54. Greulich, N., Hickmann, U., Trautmann, N., Herrmann, G.: Fast preparation and gas-chromatographic separation of lanthanide and actinide hexafluoroacetylacetonates. Fresenius Z. Anal. Chem. 323, 839-845 (1986).

55. Fedoseev, E. V., Aizenberg, M. I., Timokhin, S. N., Travnikov, S. S., Zvara, I., Davydov, A. V., Myasoedov, B. F.: Thermochromatographic separation of the products of nuclear reactions in the form of $\beta$-diketonates. J. Radioanal. Nucl. Chem. Lett. 119, 347-354 (1987).

56. Zvara, I.: Thermochromatographic method of separation of chemical elements in nuclear and radiochemistry. Isotopenpraxis $\mathbf{2 6}$, 251-258 (1990).

57. Firestone, R. B., Shirley, V. S. (eds.): Table of Isotopes. $8^{\text {th }}$ Edn., John Wiley and Sons, Inc., New York (1996).

58. Leitner, D., McMahan, M. A., Argento, D., Gimpel, T., Guy, A., Morel, J., Siero, R., Thatcher, R., Lyneis, C. M.: Heavy ion cocktail beams at the 88-Inch Cyclotron. Lawrence Berkeley National Laboratory Report LBNL-51451. Lawrence Berkeley National Laboratory, Berkeley, CA (2002), p. 1-4.

59. Leitner-Wutte, D., McMahan, M. A., Argento, D., Gimpel, T., Guy, A., Morel, J., Siero, R., Thatcher, R., Lyneis, C. M.: Heavy ion cocktail beams at the 88 -Inch Cyclotron. In: Proc. $15^{\text {th }}$ Int. Workshop on ECR Ion Sources, ECRIS '02, Jyväskylä, Finland, June 12-14 (2002), pp. 183-186.

60. Ziegler, J. F.: SRIM-2003. Nucl. Instrum. Methods B 219-220, 1027-1036 (2004).

61. Soverna, S., Dressler, R., Düllmann, Ch. E., Eichler, B., Eichler, R., Gäggeler, H. W., Haenssler, F., Niklaus, J. P., Piguet, D., Qin, Z., Türler, A., Yakushev, A. B.: Thermochromatographic studies of mercury and radon on transition metal surfaces. Radiochim. Acta 93, 1-8 (2005).

62. Bassett, J. E., Whittle, E.: The photochemistry of hexafluoroacetylacetone in the vapour phase. Occurrence of a novel HF elimination reaction. Int. J. Chem. Kinet. 8, 859-876 (1976).

63. Droes, S. R., Kodas, T. T., Hampden-Smith, M. J.: Dry etching of $\mathrm{ZnO}$ films with hexafluoroacetylacetone. Adv. Mater. 10, 11291133 (1998)

64. Russell, D. K., Yee, A.: Laser pyrolysis studies of $\beta$-diketonate chemical vapour deposition precursors. Part 1: $\beta$-diketones. New J. Chem. 29, 485-492 (2005).

65. Dressler, R., Fischer, S., Gäggeler, H. W., Bruchertseifer, H.: $\gamma$-Zerfall neutronendefiziter Isotope der Elemente Wolfram, Tantal, Hafnium und Luthetium. Datenkatalog und Spektrensamm- lung: Teil B + C. PSI-Bericht Nr. 97/04/II, ISSN 1019-0643, Paul Scherrer Institut, Villigen, Switzerland (1997), p. 97 [in German].

66. Hild, T., Schmidt-Ott, W.-D., Freystein, V., Meissner, F., Runte, E., Salewski, H., Michaelsen, R.: Spectroscopic investigation of ${ }^{164,168} \mathrm{Ta},{ }^{166} \mathrm{~W}$ and ${ }^{164,165} \mathrm{Hf}$. Nucl. Phys. A 492, 237-252 (1989).

67. Schumann, D., Dressler, R., Fischer, S., Taut, S., Binder, R., Szeglowki, Z., Kubica, B., Guseva, L. I., Tikhomirova, G. S., Constantinescu, O., Domanov, V. P., Constantinescu, M., Lien, D. T., Oganessian, Y. T., Brudanin, V. B., Bruchertseifer, H.: Sorption behaviour of short-lived $\mathrm{W}$, Hf and Ta isotopes on ion exchangers from $\mathrm{HCl} / \mathrm{HF}$ solutions in fast on-line experiments. Radiochim. Acta 69, 35-38 (1995).

68. Liang, C. F., Paris, P., Bastin, G., Obert, J., Putaux, J. C.: Online separation of refractory hafnium and tantalum isotopes at the ISOCELE separator. In: Proc. Fourth Int. Conf. Nuclei far from Stability, Helsingør, Denmark, Vol. 2, CERN Report 81-09 (1981), pp. 709-711.

69. Heller, W., Binder, R., Bruchertseifer, H., Becker, U., Habergerger, F., Herrmann, G., Kratz, J. V., Mendel, M., Nähler, A., PenseMaskow, M., Trautmann, N., Wiehl, N., Brüchle, W., Jäger, E., Schädel, M., Schausten, B., Alstad, J., Skarnemark, G., Dressler, R., Fischer, S., Roß, A., Eichler, B., Hübener, S.: Half-lives of short-lived W-, Ta- and Hf-isotopes determined in model experiments for the chemical separation of element 106. Annual Report 1991, Inst. für Kernchemie, Univ. Mainz, Germany (1992), p. 28, ISSN 0932-7622.

70. Bruchertseifer, H., Eichler, B., Estevez, J., Zvara, I.: Fast continuous radiochemical isolation of the short-lived isotopes of $\mathrm{Hf}$, Ta and $\mathrm{W}$ produced by heavy ion induced reactions. Radiochim. Acta 47, 41-46 (1989).

71. Bruchertseifer,H., Eichler, B.: Untersuchung der Produkte der Reaktion ${ }^{147} \mathrm{Sm}+{ }^{22} \mathrm{Ne}$. Radiochem. Radioanal. Lett. 48, 391-400 (1981) [in German].

72. Düllmann, Ch. E., Pang, G. K., Folden III, C. M., Gregorich, K. E., Hoffman, D. C., Nitsche, H., Sudowe, R., Zielinski, P. M.: Toward volatile metal complexes of rutherfordium - Results of test experiments with $\mathrm{Zr}$ and $\mathrm{Hf}$. In: Proc. $6^{\text {th }}$ Int. Conf. on Nuclear and Radiochemistry, NRC 6, August 29-September 3, 2004, Aachen, Germany, in: Advances in Nuclear and Radiochemistry, General and Interdisciplinary. (Qaim, S. M., Coenen, H. H., eds.) Forschungszentrum Jülich $\mathrm{GmbH}$, Jülich, Germany (2004), Vol. 3., pp. 147-149.

73. Zvara, I.: Simulation of thermochromatographic processes by the Monte Carlo method. Radiochim. Acta 38, 95-101 (1985).

74. Gorshkov, A. Graeger, R., Türler, A., Yakushev, A., Ackermann, D., Brüchle, W., Düllmann, Ch. E., Jäger, E., Heßberger, F. P., Khuyagbaatar, J., Krier, J., Schädel, M., Schausten, B., Schimpf, E., Andersson, L.-L., Rudolph, D., Eberhardt, K., Even, J., Kratz, J. V., Liebe, D., Thörle, P., Wiehl, N., Dragojević, I., Gates, J. M., Stavsetra, L., Omtvedt, J. P., Sabelnikov, A., Samadani, F., Uusitalo, J.,: Measurements of ${ }^{260-262} \mathrm{Rf}$ produced in ${ }^{22} \mathrm{Ne}+{ }^{244} \mathrm{Pu}$ fusion reaction at TASCA. GSI Scientific Report 2008, GSI Helmholtzzentrum für Schwerionenforschung, Darmstadt, Germany (2009), in print; and in preparation for submission to Phys. Rev. C.

75. Dragojević, I., et al.: in preparation for submission to Nucl. Instrum. Methods B (2008). 